\title{
Why is Spot Carbon so Cheap and Future Carbon so Dear? The Term Structure of Carbon Prices
}

\author{
Don Bredin* and John Parsons**
}

\begin{abstract}
This study examines carbon spot and futures price relationships and the dynamics of the carbon term structure in the European Union Emission Trading Scheme (ETS) between 2005-2014. Using spot and futures prices, we calculate an implied cost of carry. According to received theory, the cost of carry is-with some exceptions-just the opportunity cost of money, so that the term structure of the cost of carry should exactly equal the term structure interest rates. However, we show that spot carbon allowances were originally expensive relative to futures, but since late 2008 the situation reversed and spot carbon allowances have been persistently cheap relative to futures prices. This dramatic shift coincides with the onset of the global financial crisis in late 2008 and the ongoing European banking crisis of 2010-2013.
\end{abstract}

Keywords: $\mathrm{CO}_{2}$ prices, EU ETS, Energy, Kyoto Protocol

http://dx.doi.org/10.5547/01956574.37.3.dbre

\section{INTRODUCTION}

In January 2005 the European Union (EU) formally introduced the Emissions Trading Scheme (ETS), a multi-country cap and trade system for emissions of carbon dioxide $\left(\mathrm{CO}_{2}\right)$. Under the system a fixed quantity of allowances for emissions are issued each year. Companies covered by the system must submit allowances to match their emissions. The allowances are initially distributed either directly to targeted companies, or sold in auctions. Allowances then trade freely in the secondary market. The system's Phase 1 (Pilot Phase) covered the years 2005 to 2007, while Phase 2 (Kyoto Phase) covered the years 2008 to 2012. ${ }^{1}$ The system is now in Phase 3 covering the years 2013 to 2020. In Phase 1, companies were allowed to bank allowances from one year to the next, but all Phase 1 allowances expired at the end of the Phase. In Phase 2 companies were allowed to bank allowances for use in later years, and this banking can continue into Phase 3 and, potentially indefinitely. ${ }^{2}$

1. See Bredin and Muckley (2011) for an evaluation of market behaviour in Phase 1 and early Phase 2.

2. A number of important changes has also been implemented for Phase 3. The most significant was the introduction of a single EU wide cap which declines linearly each year by $1.74 \%$ (from 2013). Besides Phase 3 being the longest in duration relative to the previous two phases, it also formally introduces the path to complete allowance auctions. While industrials will have their free allocation phased out over time, electricity utilities will move to auctioning immediately in Phase 3. Both power station operators and combined heat and power plant operators will not be allocated allowances for free and

* Corresponding author. Professor of Finance and Chair of the Banking \& Finance Subject Area, School of Business, University College Dublin, Blackrock, Dublin, Ireland. E-mail: don.bredin@ucd.ie.

** Senior Lecturer in Finance, MIT Sloan School of Management, Massachusetts Institute of Technology, E62-684 77

Massachusetts Avenue, Cambridge, MA 02139, USA. E-mail: jparsons@mit.edu.

The Energy Journal, Vol. 37, No. 3. Copyright (C) 2016 by the IAEE. All rights reserved. 
It is the banking provision of the ETS that is central to our analysis. The only obvious cost of banking an allowance is the opportunity cost of money. Other commodities have costs of storage, but the cost of holding an allowance is nil; just the overhead involved in managing the electronic account. Other commodities have convenience yield associated with holding the physical good, which reflects the avoided cost of stock-outs or related benefits to the production process. It is hard to imagine a comparable source of convenience yield holding for a carbon allowance. Allowances are submitted annually by the 30th April, after the full inventory of the previous year's emissions is completed and reported by the 31st March. The company has plenty of time to source additional allowances that may be needed. Therefore, a casual analysis of the rules of the EU ETS would suggest that the term structure of carbon prices should be an exact duplicate of the term structure of interest rates, see Parsons et al. (2009). The data, however, contradict this theory.

Spot carbon allowances were originally expensive relative to futures, but since late 2008 the situation reversed and spot carbon allowances have been persistently cheap relative to futures prices. That is, the return to holding a carbon allowance together with a short futures position was originally less than the interest rate, but since late 2008 has been much greater than the interest rate. This relationship holds all along the futures curve, with shorter maturity futures being cheap relative to longer maturity futures. The magnitudes are quite large. This dramatic shift coincides with the onset of the global financial crisis in late 2008 and the ongoing European banking crisis of 2010-2013. These events constrained leverage and placed a high premium on liquidity, which may explain the implied cost of carry and its volatility. Alternatively, it may reflect overlooked, but important facts about market expectations for the evolution of EU ETS rules related to the banking of allowances across years. Or, it may reflect a combination of these factors.

There is a large empirical literature on the EU-ETS. Much of it focuses on the determinants of the level of the carbon price and on important events that precipitated major price changes. A number of studies have examined the relationship between spot and futures prices. These include Benz and Trück (2009), Borak et al. (2006), Uhrig-Homburg and Wagner (2009), Joyeux and Milunovich (2010), Chevallier (2010), Madalena and Pinho (2011) and Trück et al. (2012). The studies differ in how they treat the rupture in the relationship between the spot price in 2006-2007 and futures prices for delivery in 2008 and later. This rupture was a consequence of the seam between the two trading periods, where banking of allowances across years was not allowed. In some of these studies this rupture is the focus of the analysis, while in others it is included as part of the time series of the relationship between spot and futures. Our concern is the term structure when banking is allowed i.e., within Period 1 and from Period 2 onward. Consequently, we do not examine the term structure across this seam. Along this line, Uhrig-Homburg and Wagner (2009) document that carbon spot prices were expensive early in the first phase, although for the balance of the period they find long-run relationships consistent with the cost of carry model. Uhrig-Homburg and Wagner (2009), show that these results are even cleaner when looking at futures prices of different maturity.

Joyeux and Milunovich (2010) take the analysis a step further and formally test whether the coefficient values in the cointegrating equation for spot and futures prices are consistent with the cost of carry model during the first phase. Using a joint hypothesis test the authors reject the

so will be required to purchase allowances either via auction or on the secondary market. Additional benefits of auctions is the additional revenue to national governments, as opposed to revenue being retained by the polluting installations under the system of grandfathering. Since 2013, and the move to Phase 3, over $40 \%$ of all allowances will now be auctioned, with the ETS legislation setting a goal of complete phase out of free allocations by 2027.

Copyright (C) 2016 by the IAEE. All rights reserved. 
null that the coefficient on the EUA spot price and the interest rate in the cost of carry futures price relationship simultaneously equal one. Trück et al. (2012) look at data extending into the beginning of the second phase and document that the relationship switched by mid- 2009, when their data ends, so that spot prices had by then become cheap relative to futures prices. They explore using a two-factor term structure model to capture the dynamics of the convenience yield and its relationship to the spot price. We extend these results out through 2014, including the remainder of Phase 2 and into Phase 3 and show that carbon spot prices remained cheap as do shorter maturity futures relative to longer maturity futures.

We explore the use of the term structure model proposed by Nelson and Siegel (1987). The model is widely used by central banks to model interest rates, see Bank of International Settlements (2005) and European Central Bank (2008). One of the model's advantages is the reduction in the dimensionality of the data, see Diebold and Li (2006). In our case, there is little reduction in dimensionality. However, the model takes the raw time series data, which are defined by a constantly changing maturity and transforms it into a time series of parameters which are consistent through time. Both our term structure analysis and our individual contract analysis results, consistently point towards towards evidence counter to theory.

\section{SPOT AND FUTURES PRICE RELATIONS}

The theory of storage defines an arbitrage relationship between the current spot price and the current futures price for a commodity (see Brennan, 1958). Assume an investor purchases a commodity at the current spot price, $S_{t}$, planning to hold it over a window of time, $\tau$, to period $T=t+\tau$. The investor pays the current cost of storage for window of time, $\tau, K_{t}(\tau)$ earns the current convenience yield for window of time $\tau, \Psi_{t}(\tau)$, and anticipates receiving the spot price at $T, S_{T}$ (see Pindyck, 2001). The payoff on this investment is:

$$
S_{T}-K_{t}(\tau)+\Psi_{t}(\tau)-S_{t}
$$

Since this payoff varies with the commodity spot price at $T, S_{T}$, it is risky. Assume now that the investor also sells short one futures contract for the commodity maturing at $T$, agreeing to pay the difference between the futures price today, $F_{t}(\tau)$ and the price at maturity, $F_{T}(0)=S_{T}$. The payoff on this investment is:

$$
-\left(F_{T}(0)-F_{t}(\tau)\right)=F_{t}(\tau)-S_{T}
$$

This payoff also varies with the commodity spot price at $T$, with an exposure exactly opposite to the first payoff. The combined payoff is:

$$
F_{t}(\tau)-S_{t}-K_{t}(\tau)+\Psi_{t}(\tau)
$$

This is a riskless payoff. By arbitrage this riskless payoff should equal the payoff to investing the cost of the commodity in a riskless bond, i.e., the spot interest rate for maturity $\tau$, $Y_{t}(\tau)$

$$
F_{t}(\tau)-S_{t}-K_{t}(\tau)+\Psi_{t}(\tau)=Y_{t}(\tau)
$$


While most physical commodities have substantial costs of storage, the cost of storing EUAs is essentially zero. Therefore, we proceed with $K_{t}(\tau)=0$. Expressing the interest rate and the convenience yield as continuously compounded spot rates, $y_{t}(\tau)$ and $\psi_{t}(\tau)$, and rearranging, we can restate this equality as:

$$
F_{t}(\tau)=S_{t} \exp \left(\left(y_{t}(\tau)-\psi_{t}(\tau)\right) \tau\right)
$$

Since EUAs can be banked from one period to the next, an argument can be made that the convenience yield should be zero, $\psi_{t}(\tau)=0$. In that case, the futures price equals the spot price grown at the spot interest rate:

$$
F_{t}(\tau)=S_{t} \exp \left(y_{t}(\tau) \tau\right)=Z_{t}\left(\tau, S_{t}, y_{t}(\tau)\right)
$$

We call $Z_{t}$ the cost of carry futures price. An alternative way to look at the same relationship is to calculate the implied continuously compounded spot convenience yield:

$$
\psi_{t}(\tau)=y_{t}(\tau)-\frac{1}{T-t} \ln \left(\frac{F_{t}(\tau)}{S_{t}}\right)
$$

If the observed futures price is above the cost of carry price, then the implied convenience yield is negative and we say that the futures contract is expensive and the spot is cheap. If the futures price is below the cost of carry price, then the implied convenience yield is positive and we say that the futures contract is cheap and the spot is expensive.

The arbitrage argument applies to any investor, including those with no natural long position as an emitter of carbon and with no endowment of carbon allowances, but it is predicated on the ability to borrow at a risk-free rate in order to construct the riskless portfolio of a spot purchase and a future delivery obligation. An alternative approach not based on arbitrage is to understand the risk-return tradeoffs facing an industrial or electricity generation company that, because it expects to emit carbon in futures years, is short a future carbon allowance, but also has a surplus of spot carbon allowances. If the company holds on to its surplus spot allowance, it can cover its future obligation. Alternatively, if the company sells its spot allowances now, it opens an exposure to the uncertain cost of covering its short position in the future. So, the price at which it is willing to sell spot reflects the risk-return tradeoff it is willing to make. This tradeoff includes any premium the company may place on cash today. In this approach, the implied convenience yield is a measure of that premium and reflects the financial constraints facing the companies that are the marginal holders of allowances. The implied convenience yield should only equal zero if these companies face no financial constraints. If they do face constraints so that there is a positive premium placed on cash, then the implied convenience yield may be positive. Changes in financial constraints will be reflected in changes to the implied convenience yield.

There are a number of data problems that arise in working with spot and futures prices. Several flow from the fact that the spot market is institutionally separate from the futures market. Consequently, reported prices may not be exactly comparable, e.g. they may be for trades at different times, may impound different minimum price increments and may reflect the different liquidity in the two markets. This adds noise to the spot-futures price relationship that may confound efforts to accurately measure the implied convenience yield. 
One way to work around this problem is to shift away from the spot market and examine the relationships among futures prices with different maturities, $F_{t}\left(\tau_{1}\right)$ and $F_{t}\left(\tau_{2}\right)$. An arbitrage argument similar to the one that establishes the spot-futures cost of carry formula can be applied to successive futures prices. In this case, instead of working with the spot interest rate, $y_{t}(\tau)$, we are working with the forward interest rate, $\eta_{t}\left(\tau_{1}, \tau_{2}-\tau_{1}\right)$ and instead of working with the spot convenience yield, $\psi_{t}(\tau)$, we are working with the forward convenience yield, $\varphi_{t}\left(\tau_{1}, \tau_{2}-\tau_{1}\right)$ :

$$
F_{t}\left(\tau_{2}\right)=F_{t}\left(\tau_{1}\right) \exp \left(\left(\eta_{t}\left(\tau_{1}, \tau_{2}-\tau_{1}\right)-\varphi_{t}\left(\tau_{1}, \tau_{2}-\tau_{1}\right)\right)\left(\tau_{2}-\tau_{1}\right)\right)
$$

If we assume that the forward convenience yield is zero, then we have:

$$
F_{t}\left(\tau_{2}\right)=F_{t}\left(\tau_{1}\right) \exp \left(\eta_{t}\left(\tau_{1}, \tau_{2}-\tau_{1}\right)\left(\tau_{2}-\tau_{1}\right)\right)=\zeta_{t}\left(\tau_{1}, \tau_{2}-\tau_{1}, F_{t}\left(\tau_{2}\right), \eta_{t}\left(\tau_{1}, \tau_{2}-\tau_{1}\right)\right)
$$

where $\zeta_{t}$ is the cost of carry futures price for the later maturity contract.

The implied convenience yield formula is:

$$
\varphi_{t}\left(\tau_{1}, \tau_{2}-\tau_{1}\right)=\eta_{t}\left(\tau_{1}, \tau_{2}-\tau_{1}\right)-\frac{1}{\tau_{2}-\tau_{1}} \ln \left(\frac{F_{t}\left(\tau_{2}\right)}{F_{t}\left(\tau_{1}\right)}\right)
$$

If the observed futures price for the later maturity contract is above the cost of carry price, then the implied forward convenience yield is negative and we say that the later maturity futures contract is expensive and the shorter maturity contract is cheap. If the observed futures price for the later maturity contract is below the cost of carry price, then the implied forward convenience yield is positive and we say that the later maturity futures contract is cheap and the shorter maturity contract is expensive. Examining forward rates can provide more detailed information on the convenience yield. Spot rates are a complicated average of forward rates, so the implied convenience yield from spot rates is an average of the implied forward convenience yields. Looking at the separate elements can be informative.

\section{EXAMINATION OF THE IMPLIED CARBON CONVENIENCE YIELD}

The EU-ETS initially covered emissions from approximately 11,500 installations accounting for approximately $45 \%$ of the $\mathrm{CO}_{2}$ emissions in 25 states of the European Union, see Ellerman et al. (2010). In Phase 1, allowances for approximately 2.18 billion tonnes of $\mathrm{CO}_{2}$ annually were distributed. In Phase 2, allowances for approximately 2.03 billion tonnes of $\mathrm{CO}_{2}$ annually were distributed. This is comparable to a cap declining at $1.8 \%$ per year over the 8 years to 2012 . The geographic coverage of the system has expanded to 31 states. The system has also been extended to additional industries. The total number of stationary installations covered was 13,500 at the end of 2013. The system also now includes some greenhouse gases besides $\mathrm{CO}_{2} \cdot{ }^{3}$ These expansions have included adjustments to the number of annual allowances being distributed. In Phase 3, which began in 2013, the cap has been reduced by 37 million tonnes of $\mathrm{CO}_{2}$ each year until 2025, a rate

3. Under the ETS an allowance provides permission to emit into the atmosphere, one tonne of carbon dioxide $\left(\mathrm{CO}_{2}\right)$ equivalent (e) over a specified trading period. $\mathrm{CO}_{2}$ e would include $\mathrm{CO}_{2}$ from power and heat generation, energy intensive industry sectors including for example oil refineries and steel plants, civil aviation, nitrous oxide $\left(\mathrm{N}_{2} \mathrm{O}\right)$ from production of nitric, adipic, glyoxal and glyoxlic acids and perfluorocarbons (PFCs) from aluminium production. See EC (2013). 
of approximately $1.74 \%$ annually. A concise review of the evolution of the system can be found in Ellerman et al. (2014).

Between 2008 and 2012, companies in the EU-ETS accumulated a bank of allowances valid for approximately 1.8 billion tonnes of $\mathrm{CO}_{2}$ (e), according to Ellerman et al. (2014). This is equal to approximately $17 \%$ of emissions over the same period. A survey by Neuhoff et al. (2012) suggests that the majority of the bank is held by the power sector with another significant portion held by the industry sector.

\subsection{Data}

Our data includes daily closing prices on EU allowance (EUA) spot and futures contracts. Our sample of data runs from 24th June 2005 to the 10th October 2014. Both spot and futures contract prices are denominated in Euro per tonne of $\mathrm{CO}_{2}$ equivalent. Our spot price data is taken from the BlueNext exchange which had $72 \%$ of the spot trading volume-see Chevallier (2009). ${ }^{4}$ Unfortunately, spot trading suffered a number of interruptions. For example, during the period 49 June 2009 BlueNext trading was suspended due to a VAT fraud. Then, between 19 January 2011 and 4 February 2011, a temporary suspension of the Community Independent Transaction Log (CITL) transactions led to the suspension of trading on BlueNext and other EUA spot exchanges. On 20th January 2011 it was revealed that EUAs to the value of 7 million euro had been stolen from an account in the Czech Republic, the European Commission suspended EUA spot trading to combat further fraudulent activities. ${ }^{5}$ Finally, on 5th December 2012, BlueNext closed. Therefore from 11 May 2012 onwards we adopt the spot price from the EEX. ${ }^{6}$

The EUA futures data is from the European Climate Exchange (ECX) in London which is listed on the ICE Futures Europe's trading platform (Intercontinental Exchange). ${ }^{7}$ A EUA futures contract is an agreement to deliver a specified quantity of allowances at a specified future date. The

4. BlueNext was established in December 2007 when NYSE Euronext and Caisse des Depots purchased the carbon market from PowerNext.

5. A critical issue in relation to the fraudulent activities is that EUA spot contracts, unlike EUA futures contracts, are not considered a financial asset. The implication is that EUA spot transactions are not protected by an EU financial regulator and are subject to VAT. With the planned introduction of the Markets in Financial Instruments Directive (MiFID) 2, EUA spot instruments will now be defined as a financial instrument. EU allowances (both spot and futures) are not accepted as collateral for Eurosystem credit operations. The eligibility criteria for collateral, including further information on the different eligibility criteria are specified in the 'General documentation on Eurosystem monetary policy instruments and procedures', Chapter 6. A list is published and updated daily on the ECB's website. In addition the planned actions on the legislation in relation to capital requirements for EU allowances are only applicable to credit institutions and investment firms. For those trading for compliance on the ETS, there will be no such capital requirements under the revised rules. However, banks and speculators will have to seek regulatory approval given their trading in EUA spot is unlikely to be ancillary.

6. In addition to the breaks in trading, the spot price was subject to a number of structural breaks. For example on the 25 April 2006, there was an unofficial release of the 2005 emissions data by some of the EU member states, namely the Netherlands, Czech Republic, France, and Spain. The unofficial announcement indicated considerable long positions and led to a considerable price fall. EU ETS spot prices had reached a high of 30.50 euro prior to April 2006. Following the official release by the EU commission on the 15th May 2006, showing a larger than expected surplus in the market (confirmed verified emissions were 4\% lower than yearly allocations), the spot price fell to 15.63 euro on the 17th May 2006 (see Ellerman and Buchner, 2007). Given that banking EUA's was prohibited between phases, the price eventually converged to close to zero at the end of Phase 1. Ellerman and Joskow (2008) indicate that the April 2007 release of verified emissions for 2006 had no effect on EUA prices.

7. EUA futures also trade on the European Energy Exchange (Leipzig), however, the vast majority of EUA futures trading takes place on the ECX and it is considered to be more liquid than the EEX.

Copyright (C) 2016 by the IAEE. All rights reserved. 


\section{Figure 1: EU ETS Spot and Futures Prices}
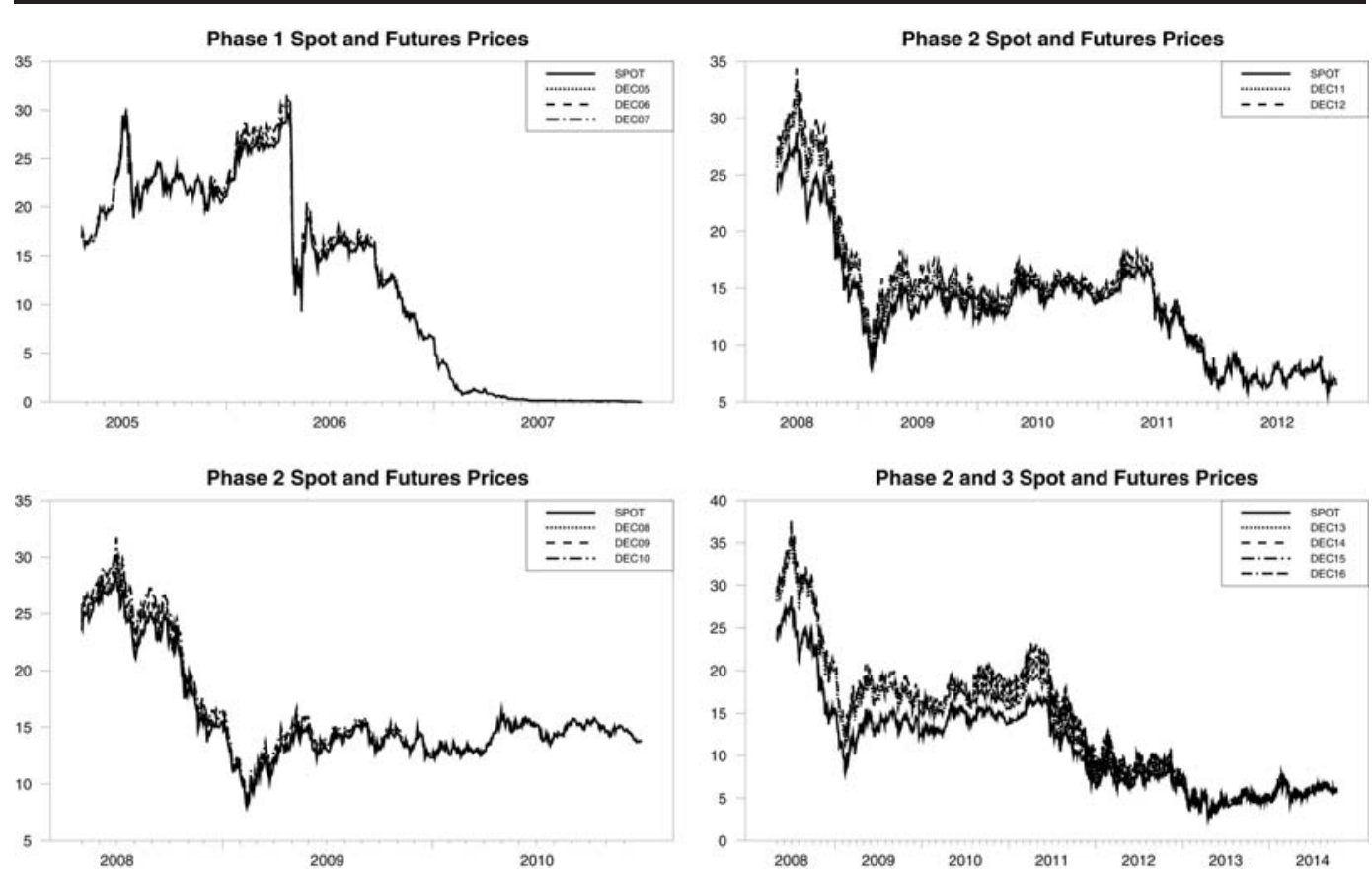

units of trading is one lot of 1,000 $\mathrm{CO}_{2}$ EU Allowances, with each EUA being an entitlement to emit one tonne of carbon dioxide equivalent gas. The expiration is the last Monday of the following contract months; March, June, September and December. Given the considerably larger volume on December expiring contracts (over $90 \%$ of all volumes), we focus exclusively on December expiring contracts; December 2005 through to December 2016. Our sample of data therefore includes EU ETS Phase 1, 2 (Kyoto) and 3 contracts. ${ }^{8}$ The complete price series for both the EUA spot and futures prices for both Phase 1 and Phase 2 sample of data are reported in Figure 1. The figure for Phase 1, highlights the collapse in the price following the official announcement indicating over supply in May 2006. Prices peaked during the summer of 2008, but declined dramatically since then. Following a short rebound in early 2009, there has been a sustained period of stabilization until mid 2011. For the remainder of 2011 the price fell considerably, with a stabilization between 10 and 5 euros for the remainder of 2012 and a further fall and stabilization around the 5 euro mark from 2013 into 2014. The dramatic price fall in 2008 has led to considerable debate in both academic and policy circles, as to the causes and the implications for the EU ETS see, Clo et al. (2013) and Grosjean et al. (2014). ${ }^{9}$ Koch et al. (2014) examine the role of the economic recession, EU renewable policy and international offsets. The authors find only economic fundamentals and the growth in renewables can explain the EU ETS price movement, although the goodness of fit is quite low.

8. There is no restrictions (banking or borrowing) to EUA trading intra-phase throughout our analysis and no banking restrictions inter-phase since the start of the Kyoto Phase.

9. Neuhoff et al. (2012) categories the ETS trading agents in the standard fashion as; hedgers, arbitrageurs and speculators. Using survey data, the authors indicate the expected returns for hedgers to be $5 \%$ per annum and in excess of 10 $15 \%$ for speculators. Neuhoff et al. (2012) highlight that the fall in prices are consistent with a market where the supply of allowances are exceeding hedging demand and so driving expected returns higher. 
Table 1: Summary Statistics-EUA Spot Daily Volume

\begin{tabular}{lrrrr}
\hline Year & \multicolumn{1}{c}{ Mean } & Stan. Dev. & \multicolumn{1}{c}{ Max } & Min \\
\hline Phase 1 & & & & \\
2005 & 33,814 & 28,569 & 160,000 & 0 \\
2006 & 127,837 & 105,064 & 731,000 & 0 \\
2007 & 97,782 & 139,978 & $1,127,000$ & 0 \\
Phase 2 & & & & \\
2008 & 388,013 & 486,031 & $2,039,000$ & 0 \\
2009 & $4,279,910$ & $3,648,393$ & $19,846,000$ & 0 \\
2010 & $1,050,128$ & 698,664 & $3,375,000$ & 0 \\
2011 & 176,152 & 163,839 & $1,137,000$ & 0 \\
2012 & 136,761 & 106,281 & 511,000 & 0 \\
2012 & 33,783 & 158,675 & $2,045,000$ & 0 \\
Phase 3 & & & & \\
2013 & 49,000 & 103,000 & $1,061,000$ & 0 \\
2014 & 81,000 & 57,000 & 382,000 & 0 \\
\hline
\end{tabular}

For Phase 1 and 2, the spot data is from the BlueNext exchange and is available from 24 June 2005 to 10 May 2012. For remainder of Phase 2 and Phase 3, the spot data is from European Energy Exchange (EEX). Our sample of data runs until 14 October 2014. The table reports mean, standard deviation, maximum and minimum daily volumes for EU Allowances. An EUA is an entitlement to emit one tonne of carbon dioxide equivalent gas. All statistics cover each calender year of Phase 1 and Phase 2. There are a number of breaks in the availability of spot data. See section 3.1 for details. The spike in spot trading for the year 2009, over 4 million EUAs, is driven by the VAT fraud trading activity between January and May 2009. See Section 3 for a discussion.

Exchange trading volumes in EU emission allowances spot and futures has increased from under 100 million tonnes in 2005 to over 4 billion tonnes by 2012. Trade in allowances in the spot market has been significant, see Table 1, with a peak of almost 20 million allowances traded on 2nd June 2009 on the BlueNext exchange. ${ }^{10}$ Since that date the volumes on the spot market have fallen considerably. As can be seen from Table 2, the volume of EUA futures contracts traded has grown significantly, with average daily volume increasing from under 1,000 for Phase 1 contracts to over 15,000 for Phase 2 contracts. Unlike the case of spot, there is no evidence of any decline during Phase 2. Other more informative measures of liquidity, using transaction level data, indicate a similar trend. For example, summary statistics reported in Bredin et al. (2014a) highlight that the average bid-ask spread (in euros) has fallen throughout Phase 2 of the EU ETS. Results in Bredin et al. (2014a) indicate that the average bid-ask spread (in euros) has fallen from 0.040 for the December 2008 contract to 0.015 for the December 2012 contract. A consistent result is also found for duration (time between consecutive trades). Bredin et al. (2014a) indicate that the average duration per trade (in seconds) has fallen from 51.68 for the December 2008 contract to 26.44 for the December 2012 contract. The finding of continuing market development and increasing levels of market liquidity is also reported in Kalaitzogloua and Ibrahimb (2013) and Bredin et al. (2014b).

Table 3 and 4 report summary statistics of 60 day volatility. The tables indicate a large spike in 2007, which was discussed above, but there is general consistency in volatility for spot

10. The spike in spot trading on the BlueNext exchange for the year 2009 is very much dominated by large (and volatile) trading activity between January and May 2009. This was a period of high value added tax (VAT) fraud activity and culminated in the temporary closure of the BlueNext exchange on the 8th and 9th June 2009. See Nield and Pereira (2011) for a complete discussion of VAT fraud in the EU ETS. 
Table 2: Summary Statistics-EUA Futures Daily Volume

\begin{tabular}{lrcrr}
\hline Futures Instrument & Mean & Stan. Dev. & Max & Min \\
\hline Phase 1 & & & & \\
December 2005 & 310 & 251 & 1,512 & 1 \\
December 2006 & 897 & 657 & 5,487 & 153 \\
December 2007 & 470 & 506 & 3,984 & 3 \\
Phase 2 & & & & \\
December 2008 & 5,558 & 2,359 & 17,672 & 519 \\
December 2009 & 10,795 & 3,918 & 26,910 & 1,065 \\
December 2010 & 11,796 & 5,432 & 34,317 & 1,664 \\
December 2011 & 13,318 & 6,488 & 52,209 & 1,342 \\
December 2012 & 15,361 & 6,075 & 52,581 & 2,073 \\
Phase 3 & & & & \\
December 2013 & 15,359 & 7,639 & 54,135 & 2,874 \\
December 2014 & 15,060 & 8,949 & 73,235 & 2,442 \\
December 2015 & 3,389 & 2,344 & 18,466 & 243 \\
December 2016 & 1,752 & 1,730 & 16,118 & 50 \\
\hline
\end{tabular}

Our sample of data runs from 24 June 2005 to the 14 October 2014. The unit of trading is one lot of 1,000 $\mathrm{CO}_{2}$ EU Allowances, with each EUA being an entitlement to emit one tonne of carbon dioxide equivalent gas. The table reports mean, standard deviation, maximum and minimum daily volumes for EUA Futures contracts. All statistics cover the expiring years only, with the exception of December 2015 and December 2016 contracts which are for 2014 only.

\begin{tabular}{lccc} 
Table 3: $\begin{array}{l}\text { Summary Statistics-EUA Spot Daily } \\
\text { Volatility }\end{array}$ & & \\
\hline Year & Mean & Max & Min \\
\hline Phase 1 & & & \\
2005 & $37.76 \%$ & $59.75 \%$ & $27.89 \%$ \\
2006 & $65.65 \%$ & $156.94 \%$ & $20.47 \%$ \\
2007 & $147.11 \%$ & $268.45 \%$ & $49.30 \%$ \\
Phase 2 & & & \\
2008 & $36.07 \%$ & $50.62 \%$ & $24.22 \%$ \\
2009 & $46.00 \%$ & $74.00 \%$ & $25.61 \%$ \\
2010 & $27.90 \%$ & $38.60 \%$ & $17.95 \%$ \\
2011 & $31.38 \%$ & $68.98 \%$ & $12.72 \%$ \\
2012 & $54.78 \%$ & $79.28 \%$ & $33.93 \%$ \\
Phase 3 & & & \\
2013 & $80.05 \%$ & $137.50 \%$ & $41.73 \%$ \\
2014 & $47.94 \%$ & $76.15 \%$ & $27.96 \%$ \\
\hline
\end{tabular}

Our sample of data runs from 24 June 2005 to the 14 October 2014. The unit of trading is one lot of 1,000 $\mathrm{CO}_{2}$ EU Allowances, with each EUA being an entitlement to emit one tonne of carbon dioxide equivalent gas. The table reports mean, maximum and minimum 60 day volatility for EUA Futures contracts. All statistics cover the expiring years only.

and futures throughout Phase 2. The Phillips-Perron (1988) and Lumsdaine-Papell (1997) unit root test are reported in Table 5. The test statistics are reported for each of the series in levels, with logarithmic differences in square brackets. The Lumsdaine-Papell (1997) unit root test, allows for two breaks in the intercept, the trend or both at unknown locations. With the exception of first two 
Table 4: Summary Statistics—EUA Futures Daily Volatility

\begin{tabular}{lrrr}
\hline Futures Instrument & Mean & Max & Min \\
\hline Phase 1 & & & \\
December 2005 & $45.85 \%$ & $61.14 \%$ & $26.30 \%$ \\
December 2006 & $69.43 \%$ & $165.94 \%$ & $20.96 \%$ \\
December 2007 & $150.64 \%$ & $470.87 \%$ & $50.57 \%$ \\
Phase 2 & & & \\
December 2008 & $33.08 \%$ & $50.00 \%$ & $21.85 \%$ \\
December 2009 & $46.21 \%$ & $75.13 \%$ & $26.58 \%$ \\
December 2010 & $28.52 \%$ & $39.19 \%$ & $18.32 \%$ \\
December 2011 & $30.73 \%$ & $52.76 \%$ & $14.92 \%$ \\
December 2012 & $53.34 \%$ & $77.05 \%$ & $34.84 \%$ \\
Phase 3 & & & \\
December 2013 & $44.12 \%$ & $141.37 \%$ & $14.14 \%$ \\
December 2014 & $44.61 \%$ & $140.29 \%$ & $13.42 \%$ \\
December 2015 & $50.87 \%$ & $137.98 \%$ & $12.74 \%$ \\
December 2016 & $49.76 \%$ & $136.02 \%$ & $12.13 \%$ \\
\hline
\end{tabular}

Our sample of data runs from 24 June 2005 to the 14 October 2014. The unit of trading is one lot of $1,000 \mathrm{CO}_{2}$ EU Allowances, with each EUA being an entitlement to emit one tonne of carbon dioxide equivalent gas. The table reports mean, maximum and minimum 60 day volatility for EUA Futures contracts. All statistics cover the expiring years only, with the exception of Phase 3 contracts, December 2015 and December 2016, which adopt 2014 as the expiring year.

contracts in Phase 1, all contracts indicate that the price series are non-stationary and that logarithmic differences are stationary.

The interest rate data is for the Euro area (Austria, Belgium, Cyprus, Estonia, Finland, France, Germany, Greece, Ireland, Italy, Latvia, Lithuania, Luxembourg, Malta, The Netherlands, Portugal, Slovenia, Slovakia and Spain) and is obtained from the European Central Bank via Bloomberg. We use the relevant continuously compounded risk free rates ( 3 month, 6 month, 9 month, 1 , 2, 3, 4, 5, 6, 7, 8, 9 and 10 year). ${ }^{11}$ Suitable spot rates, given the particular time horizon, are extracted using the Nelson and Siegel (1987) model.

Our overall sample of data (24th June 2005 to 10th October 2014) includes the complete sample of trading on the EU ETS from pilot to full implementation, but also a period of considerable economic and financial difficulty across Europe. The most severe time period for Europe was the 5 years between 2007 and 2012, with stagnant economic growth, considerable public and private debt and most worrying of all, price deflation. As highlighted by Shambaugh (2012), events in Europe represent three interlinked crisis; an economic growth crisis, a banking crisis and a sovereign debt crisis. The interlinked nature of the three crises is critical, with for example lower economic growth increasing the extent of non-performing loans and further amplifying the debt crisis and in the case of Europe the debt burdens of sovereign governments. European banks who sustained two decades of consistent internationalization are now having to pare back their balance sheets, by reducing leverage, raising capital, and reducing non-deposit liabilities. The combination of the three

11. Complete details on the Euro area yield curve are detailed by the ECB in the following; http://www.ecb.europa.eu/ stats/money/yc/html/technical-notes.pdf. 
Table 5: Unit Root Test Results

\begin{tabular}{|c|c|c|c|c|}
\hline \multirow[b]{2}{*}{ Phase 1} & \multicolumn{2}{|c|}{ Phillips-Perron } & \multicolumn{2}{|c|}{ Lumsdaine-Papell } \\
\hline & & & & \\
\hline Dec. 2005 & -2.442 & {$\left[-8.566^{*}\right]$} & $-6.023 *$ & {$[-10.407 *]$} \\
\hline Spot & -2.447 & {$\left[-9.207^{*}\right]$} & $-5.395^{*}$ & {$\left[-8.816^{*}\right]$} \\
\hline Dec. 2006 & -0.205 & {$[-16.552 *]$} & -4.704 & {$[-8.864 *]$} \\
\hline Spot & -0.214 & {$[-17.799 *]$} & -4.706 & {$[-9.199 *]$} \\
\hline Dec. 2007 & -2.406 & {$\left[-27.253^{*}\right]$} & -3.488 & {$[-19.902 *]$} \\
\hline Spot & -1.436 & {$[-27.059 *]$} & -3.527 & {$\left[-11.565^{*}\right]$} \\
\hline \multicolumn{5}{|l|}{ Phase 2} \\
\hline Dec. 2008 & 0.284 & {$[-12.774 *]$} & -3.297 & {$[-6.661 *]$} \\
\hline Spot & 0.271 & {$[-12.963 *]$} & -3.461 & {$\left[-6.515^{*}\right]$} \\
\hline Dec. 2009 & -1.277 & {$[-8.307 *]$} & -3.813 & {$\left[-12.516^{*}\right]$} \\
\hline Spot & -1.210 & {$[-18.908 *]$} & -3.958 & {$[-12.521 *]$} \\
\hline Dec. 2010 & -1.724 & {$\left[-10.665^{*}\right]$} & -4.574 & {$[-15.884 *]$} \\
\hline Spot & -1.842 & {$[-10.667 *]$} & -4.775 & {$\left[-15.846^{*}\right]$} \\
\hline Dec. 2011 & -0.329 & {$[-28.624 *]$} & -2.029 & {$[-23.794 *]$} \\
\hline Spot & -0.492 & {$[-28.750 *]$} & -1.954 & {$[-24.121 *]$} \\
\hline Dec. 2012 & -0.861 & {$[-33.000 *]$} & -3.323 & {$\left[-16.133^{*}\right]$} \\
\hline Spot & -1.127 & {$[-33.517 *]$} & -3.458 & {$[-16.118 *]$} \\
\hline \multicolumn{5}{|l|}{ Phase 3} \\
\hline Dec. 2013 & -0.962 & {$[-36.367 *]$} & -3.583 & {$[-19.184 *]$} \\
\hline Spot & -1.273 & {$[-36.209 *]$} & -3.461 & {$\left[-19.410^{*}\right]$} \\
\hline Dec. 2013 & -1.382 & {$\left[-39.186^{*}\right]$} & -3.813 & {$[-20.620 *]$} \\
\hline Spot & -1.517 & {$\left[-39.045^{*}\right]$} & -3.958 & {$[-20.787 *]$} \\
\hline Dec. 2014 & -1.381 & {$\left[-39.186^{*}\right]$} & -4.574 & {$[-20.620 *]$} \\
\hline Spot & -1.517 & {$\left[-39.045^{*}\right]$} & -4.775 & {$[-20.787 *]$} \\
\hline Dec. 2015 & -1.381 & {$[-31.750 *]$} & -2.029 & {$[-16.837 *]$} \\
\hline Spot & -1.517 & {$\left[-39.045^{*}\right]$} & -1.954 & {$[-20.787 *]$} \\
\hline Dec. 2016 & -1.343 & {$[-31.527 *]$} & -3.323 & {$\left[-16.735^{*}\right]$} \\
\hline Spot & -1.568 & {$[-31.490 *]$} & -3.458 & {$\left[-17.125^{*}\right]$} \\
\hline
\end{tabular}

The Phillips-Perron (PP) unit root test statistics and Lumsdaine-Papell (LP) unit root test statistics are reported. The test statistics are reported for each of the series in levels, with logarithmic differences in square brackets. A * indicates statistical significance at the $5 \%$ level.

interlinked crises, as highlighted by Shambaugh (2012), have led to considerable uncertainty in European financial markets. We will return to these issues when we discuss our empirical results.

\subsection{Spot Futures Contract Relationships}

As discussed in section 2, with riskless arbitrage the cost of carry futures price should equal the actual futures price in equilibrium and the implied yield (carbon yield) should equal the opportunity cost of money. Alternatively, without riskless arbitrage, the implied convenience yield reflects the premium to risk-free borrowing rates which reflects financing constraints. To measure the opportunity cost of money, we initially used yields on government issues. After presenting the results, we discuss the impact of using alternative measures.

The Johansen (1988) cointegration tests will examine whether these relationships hold in the long-run. ${ }^{12}$ Taking logs of equation (5):

12. The Johansen (1988) cointegration test examines the relationship between the rank of a matrix and its characteristic roots. It involves the performance of likelihood ratio tests on the rank of the long-run information matrix, $\pi$. These statistical tests provide an estimate of the number of characteristic roots that are different from zero. We also examine the Johansen small correction test, Trace Bartlett statistic which is derived in Johansen (2002). 
Table 6: Cointegration-Actual and Cost of Carry Futures Price

\begin{tabular}{|c|c|c|c|}
\hline Instrument & Trace Test & Trace Bartlett Test & Gregory-Hansen Test \\
\hline$F^{05}, T F^{05}$ & $\begin{array}{c}87.665^{*} \\
(0.000)\end{array}$ & $\begin{array}{c}85.020 * \\
(0.000)\end{array}$ & -5.514 \\
\hline$F^{06}, T F^{06}$ & $\begin{array}{c}26.330 * \\
(0.042)\end{array}$ & $\begin{array}{c}25.528^{*} \\
(0.050)\end{array}$ & $-14.455^{*}$ \\
\hline$F^{07}, T F^{07}$ & $\begin{array}{c}18.155 \\
(0.341)\end{array}$ & $\begin{array}{c}17.518 \\
(0.385)\end{array}$ & -2.126 \\
\hline$F^{08}, T F^{08}$ & $\begin{array}{l}18.445 \\
(0.321)\end{array}$ & $\begin{array}{l}17.562 \\
(0.382)\end{array}$ & $-13.840 *$ \\
\hline$F^{09}, T F^{09}$ & $\begin{array}{l}14.942 \\
(0.586)\end{array}$ & $\begin{array}{c}14.588 \\
(0.615)\end{array}$ & -3.748 \\
\hline$F^{10}, T F^{10}$ & $\begin{array}{l}18.408 \\
(0.324)\end{array}$ & $\begin{array}{l}18.104 \\
(0.344)\end{array}$ & -3.908 \\
\hline$F^{11}, T F^{11}$ & $\begin{array}{l}16.430 \\
(0.467)\end{array}$ & $\begin{array}{l}16.224 \\
(0.483)\end{array}$ & -4.467 \\
\hline$F^{12}, T F^{12}$ & $\begin{array}{c}20.430 \\
(0.208)\end{array}$ & $\begin{array}{c}20.383 \\
(0.211)\end{array}$ & -4.651 \\
\hline$F^{13}, T F^{13}$ & $\begin{array}{c}23.300 \\
(0.101)\end{array}$ & $\begin{array}{c}23.222 \\
(0.103)\end{array}$ & -4.575 \\
\hline$F^{14}, T F^{14}$ & $\begin{array}{c}21.496 \\
(0.161)\end{array}$ & $\begin{array}{c}21.433 \\
(0.164)\end{array}$ & -3.661 \\
\hline$F^{15}, T F^{15}$ & $\begin{array}{c}25.402 \\
(0.060)\end{array}$ & $\begin{array}{c}25.731 \\
(0.060)\end{array}$ & -4.559 \\
\hline$F^{16}, T F^{16}$ & $\begin{array}{c}5.365 \\
(0.554)\end{array}$ & $\begin{array}{c}5.278 \\
(0.565)\end{array}$ & -3.848 \\
\hline
\end{tabular}

The second column reports the Johansen (1988) Trace statistic. The third column reports the small correction test, Trace Bartlett statistic. See Johansen (2002) for a detailed derivation. $\mathrm{P}$ values are reported in parenthesis. The fourth column reports the Gregory and Hansen (1996a,b) test statistics. The critical value at the 5\% level is -4.950 .

$$
f_{t}(\tau)=s_{t}+y_{t}(\tau) \tau=z_{t}\left(\tau, s_{t}, y_{t}(\tau)\right)
$$

Equation (11) indicates a long-run relationship between the log of futures prices and the $\log$ cost of carry futures price, i.e., that the basis is stationary. If this did not hold, arbitrage opportunities would exist. Table 6 reports the Johansen (1988) cointegration test statistics examining the $\log$ of futures prices and the log cost of carry futures price. ${ }^{13}$ Consistent with previous results in the literature there is evidence of cointegration between actual futures prices and the cost of carry futures price for Phase 1 of the EU ETS (see Uhrig-Homburg and Wagner, 2009). ${ }^{14}$ However, there is no evidence of any cointegrating relationship for any contract trading during Phase 2 and into Phase 3. In Table 6 we also present cointegration results based on the test proposed by Gregory and Hansen (1996a,b). The Gregory-Hansen (1996a,b) implements the test for cointegration allowing for a break in the cointegrating vector, see Gregory and Hansen(1996a,b). ${ }^{15}$ With the exception

13. Two test statistics are reported. The second column reports the standard Johansen (1988) Trace statistic, while the third column reports the small correction test, Trace Bartlett statistic. See Johansen (2002) for a detailed derivation.

14. Given that banking EUAs was prohibited between phases, the spot price eventually converged to close to zero by mid-late 2007 at the end of Phase 1. As a result our sample for December 2007 contract ends in the previous calender year. This is consistent with Uhrig-Homburg and Wagner (2009).

15. The Gregory-Hansen (1996a,b) test state the null hypothesis of no cointegration and the alternative of cointegration existing after allowing for a structural break. 
Table 7: Cointegration-Carbon Yields and Treasury Yields

\begin{tabular}{|c|c|c|c|}
\hline Instrument & Trace Test & Trace Bartlett Test & Gregory-Hansen Test \\
\hline$C Y^{05}, T Y^{05}$ & $\begin{array}{c}56.942 * \\
(0.000)\end{array}$ & $\begin{array}{c}56.496 * \\
(0.000)\end{array}$ & $-5.420^{*}$ \\
\hline$C Y^{06}, T Y^{06}$ & $\begin{array}{c}30.016^{*} \\
(0.013)\end{array}$ & $\begin{array}{c}29.287 * \\
(0.016)\end{array}$ & -4.213 \\
\hline$C Y^{07}, T Y^{07}$ & $\begin{array}{c}48.387^{*} \\
(0.000)\end{array}$ & $\begin{array}{c}47.936^{*} \\
(0.000)\end{array}$ & $-7.020^{*}$ \\
\hline$C Y^{08}, T Y^{08}$ & $\begin{array}{c}16.099 \\
(0.493)\end{array}$ & $\begin{array}{c}13.304 \\
(0.717)\end{array}$ & -4.568 \\
\hline$C Y^{09}, T Y^{09}$ & $\begin{array}{l}11.467 \\
(0.844)\end{array}$ & $\begin{array}{l}11.149 \\
(0.862)\end{array}$ & -4.426 \\
\hline$C Y^{10}, T Y^{10}$ & $\begin{array}{c}12.990 \\
(0.740)\end{array}$ & $\begin{array}{l}12.133 \\
(0.801)\end{array}$ & -3.929 \\
\hline$C Y^{11}, T Y^{11}$ & $\begin{array}{c}15.245 \\
(0.561)\end{array}$ & $\begin{array}{c}14.993 \\
(0.582)\end{array}$ & -2.965 \\
\hline$C Y^{12}, T Y^{12}$ & $\begin{array}{c}23.076 \\
(0.107)\end{array}$ & $\begin{array}{c}22.100 \\
(0.138)\end{array}$ & $-7.570^{*}$ \\
\hline$C Y^{13}, T Y^{13}$ & $\begin{array}{l}11.097 \\
(0.085)\end{array}$ & $\begin{array}{c}10.887 \\
(0.093)\end{array}$ & $-6.386^{*}$ \\
\hline$C Y^{14}, T Y^{14}$ & $\begin{array}{c}13.254 \\
(0.040)\end{array}$ & $\begin{array}{l}12.752 \\
(0.044)\end{array}$ & $-4.971^{*}$ \\
\hline$C Y^{15}, T Y^{15}$ & $\begin{array}{l}17.049 \\
(0.419)\end{array}$ & $\begin{array}{l}16.819 \\
(0.437)\end{array}$ & -3.846 \\
\hline$C Y^{16}, T Y^{16}$ & $\begin{array}{c}1.558 \\
(0.978)\end{array}$ & $\begin{array}{c}1.540 \\
(0.979)\end{array}$ & -2.981 \\
\hline
\end{tabular}

The second column reports the Johansen (1988) Trace statistic. The third column reports the small correction test, Trace Bartlett statistic. See Johansen (2002) for a detailed derivation. $\mathrm{P}$ values are reported in parenthesis. The fourth column reports the Gregory and Hansen (1996a,b) test statistics. The critical value at the 5\% level is -4.950 .

of the December 2008 contract, the Johansen (1988) results and the Gregory-Hansen (1996a,b) results are perfectly consistent for Phase 2 and 3.

We also examine whether a long-run stationary relationship exists between the treasury yield and the implied convenience yield, reported in Table 7. Again our results here are consistent with our price results and the Phase 1 results presented in the study by Uhrig-Homburg and Wagner (2009). An exception is the results for the last contract in Phase 2 and into Phase 3 when adopting the Gregory-Hansen (1996a,b) test, which indicates evidence of cointegration after taking account of a structural break.

A considerably more detailed analysis is required to fully explain the theoretically counter intuitive results of no cointegration when examining the price series and the majority of the yields. Figures 2 and 3 report the difference between the implied convenience yield and the treasury yield for Phase 1, 2 and 3. For example "DEC-05" is the implied convenience yield between the December 2005 futures contract and the spot contract. Although there is no immediate trend from the Phase 1 results, we do highlight the collapse in prices (spot and Phase 1 futures) during this period. ${ }^{16}$

16. Our figures are consistent with the figures reported in Uhrig-Homburg and Wagner (2009) and Trück et al. (2012), although both papers adopt a considerably smaller sample of data. See discussion of recent studies above. 
Figure 2: Phase 1 Carbon Spot Discount

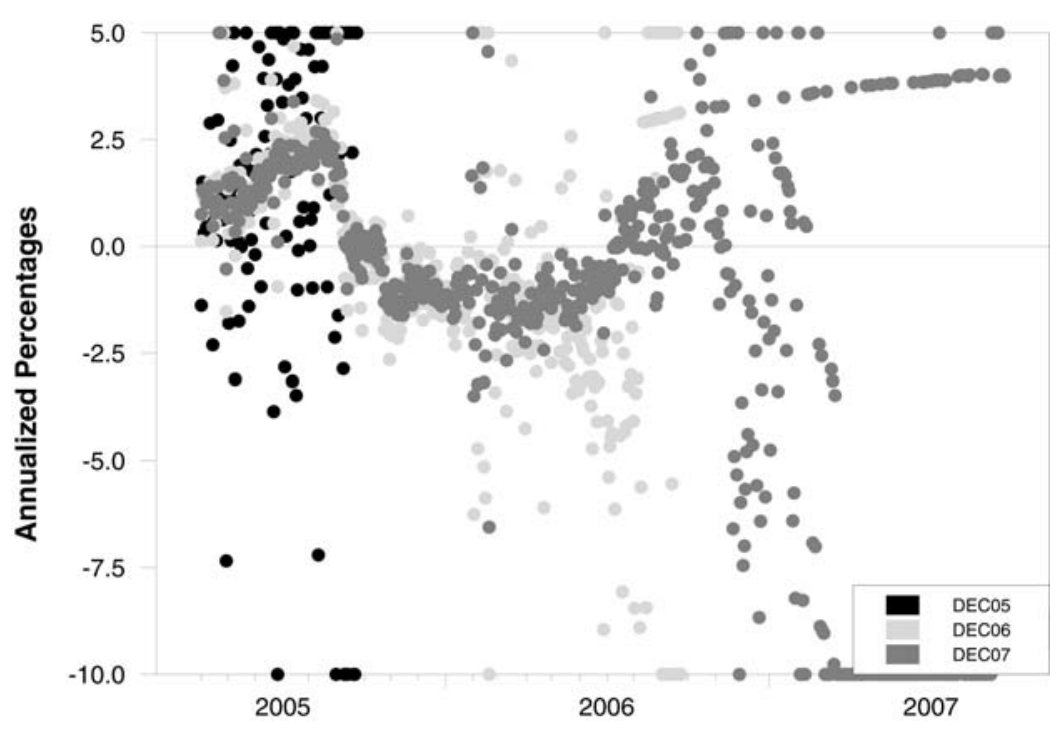

The Phase 2-3 results reported in Figure 3 offer a number of interesting points of discussion and certainly concur with the cointegration results reported previously. Firstly early in Phase 2 there is consistent evidence of a positive convenience yield, up to late 2008. ${ }^{17}$ However, this turns to a negative convenience yield for the remainder of Phase 2 and into Phase 3. This result is consistent with the results reported in Truck et al. (2012) for a sample up to July 2009. ${ }^{18}$ The negative convenience yield is persistent, although there is generally a reversion to zero (or on occasions a positive convenience yield) as we approach expiry for each of the individual futures contracts. These results are evidence of an arbitrage opportunity, assuming one could borrow at the risk-free rate. Alternatively, these results are evidence of a dramatic shift in financing constraints facing corporates who were the marginal holders of surplus allowances. The onset of the global financial crisis in 2008 and the ongoing European banking crisis of 2010-2013 certainly tightened financial constraints and increased the premium placed on cash, and this may be the cause for the increase in the implied convenience yield.

The Phase 3 contracts trading during the Phase 2 sample and into Phase 3 show a strongly negative convenience yield. While the negative convenience yield for Phase 3 futures continue to increase during the 2011 calendar year, the yields are tightly packed. ${ }^{19}$ This changes considerably during the 2012 calendar year and for the remainder of our sample, with a decline in the yield, although considerable variation now exists.

17. If the futures price is below the cost of carry price, then the implied convenience yield is positive and we say that the futures contract is cheap and the spot is expensive. If the observed futures price is above the cost of carry price, then the implied convenience yield is negative and we say that the futures contract is expensive and the spot is cheap.

18. Besides the smaller sample of data that is adopted in Trück et al. (2012), the authors examine the marginal convenience yield. Using our notation the marginal convenience yield is defined as $\gamma(\tau)=S_{t} \exp \left(y_{t}(\tau) \tau\right)-F_{t}(\tau)$.

19. There is also somewhat of a twist in the term structure in early 2011, with the discount on the nearby contract (December 2011) having a considerably larger discount than the further ahead contracts. This scenario reverts to the 'norm' in April 2011.

Copyright (C) 2016 by the IAEE. All rights reserved. 
Figure 3: Phase 2 Carbon Spot Discount
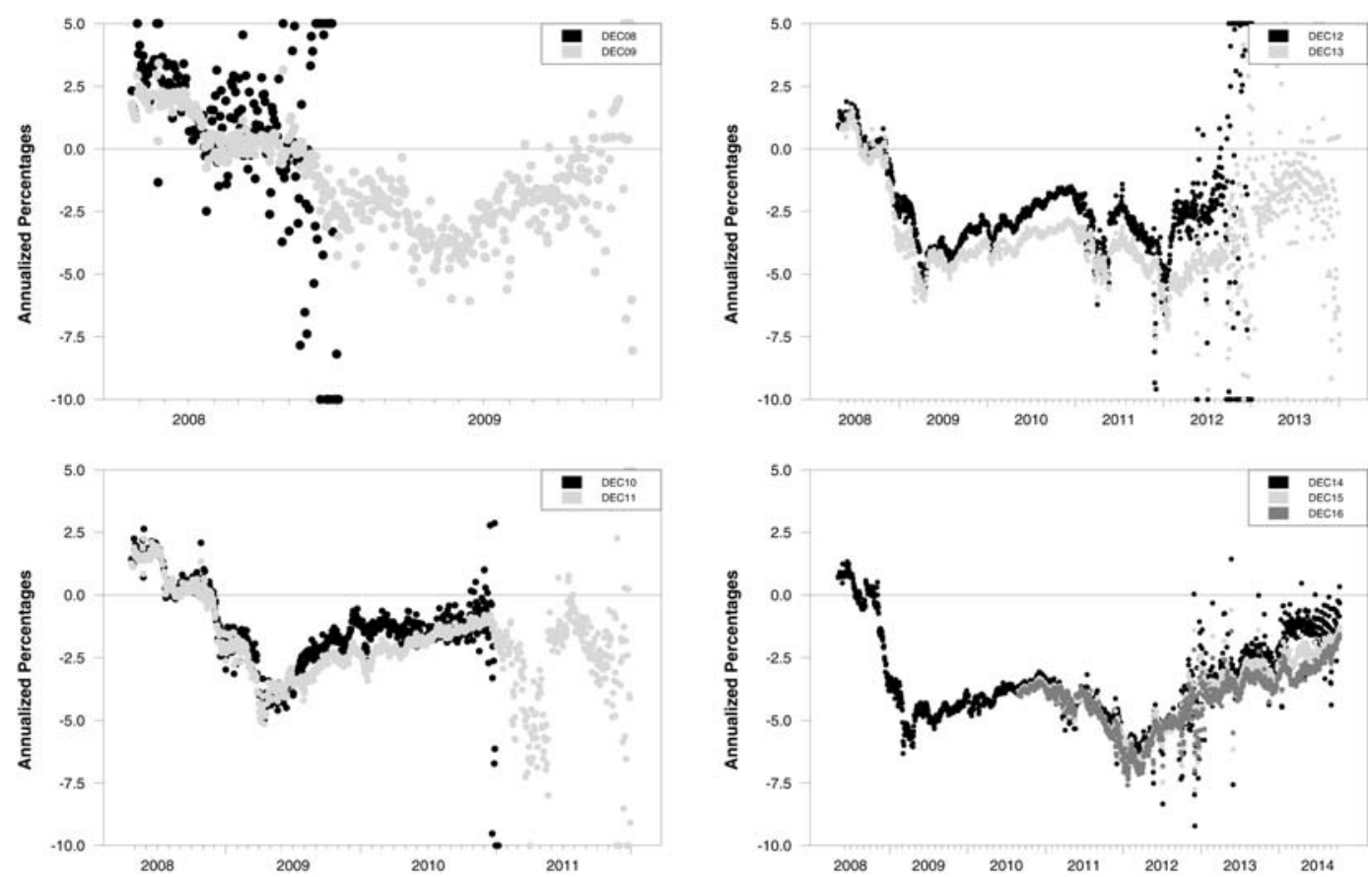

Figure 4: Phase 1 Nearby Futures Carbon Discount

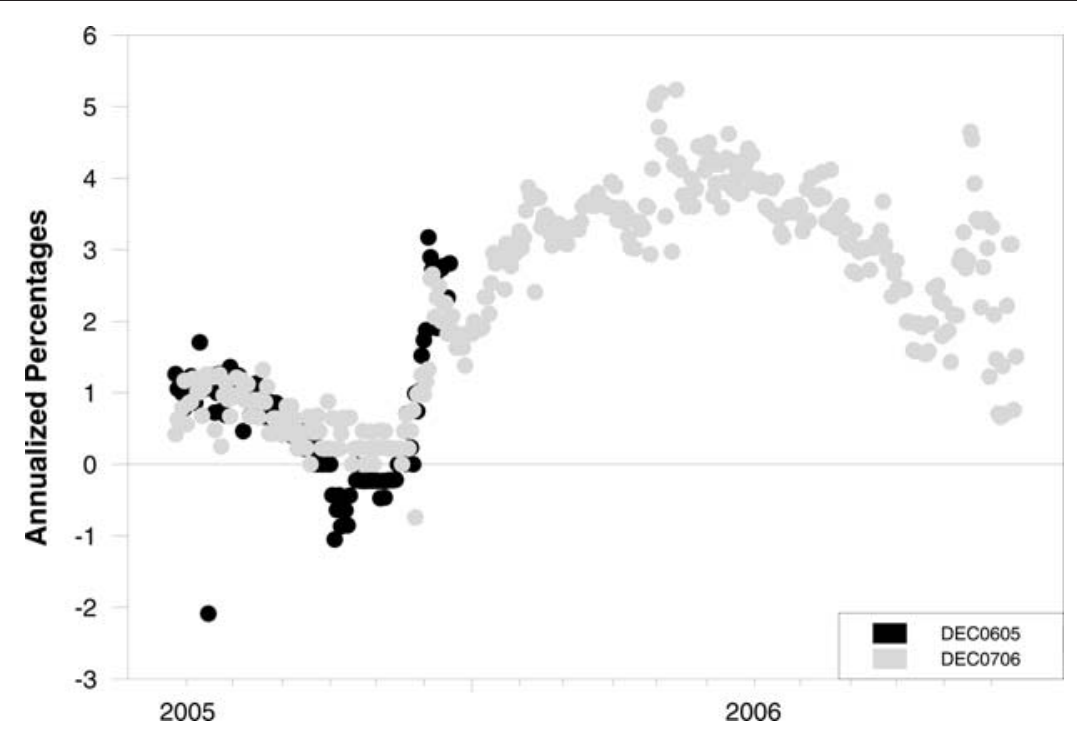

\subsection{Consecutive Futures Contract Relationships}

We now examine the extent of the implied forward convenience yields on consecutive futures contracts. The results are reporting in Figure 4 and 5. In Figure 4 and 5 the term "DEC0908" is the 1 year forward convenience yield between the December 2008 and 2009 EUA futures 
Figure 5: Phase 2 Nearby Futures Carbon Discount
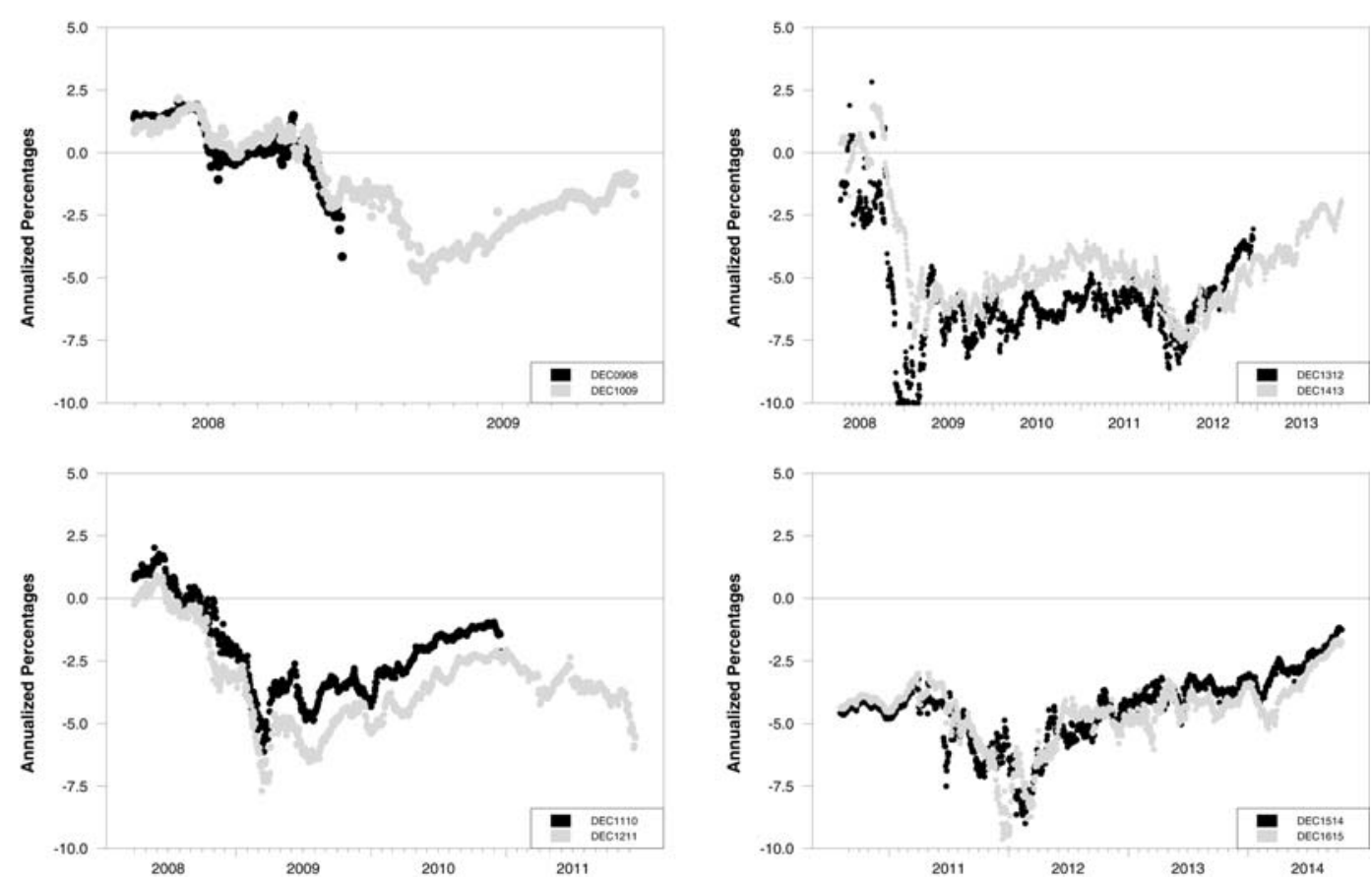

contracts. The results are generally consistent with the spot comparison, although there are some exceptions. The Phase 1 results highlight the dramatic fall in price of the December 2007 contract and give the impression of a positive forward convenience yield on the December 2006 contract, although this is more of a December 2007 contract story as it reflects the excess allowances in the market and the no-banking rule between Phase 1 and 2. The Phase 2 results again indicate evidence of a positive forward convenience yield on the short dated futures contracts early in the phase, but this turns to a persistently negative forward convenience yield from October 2008 onwards. The extent of the negative convenience yield for the December 2013-2012 ("DEC-1312") is particularly large when compared to the Phase 2 and Phase 3 comparisons. ${ }^{20}$ Our results are consistent with those reported by Neuhoff et al. (2012). Neuhoff et al. (2012) highlight the discount on nearby contracts for 2011 versus 2012 contracts to be 3-5\% and 7\% for 2012 versus 2013 contracts.

\section{A TERM STRUCTURE MODEL}

The forward convenience yields shown in Figures 4 and 5 are difficult to analyze as a whole. Each yield reported is for a year's time, but the horizon covered is changing with time. For example, in December 2008, the convenience yield defined by the December 2009 and December 2010 contracts is a one-year forward rate starting approximately one year from the current date. In June 2009, the convenience yield defined by the same two contracts is a one-year forward rate, but now starting only six months from the current date. In November 2009 it is a one-year forward rate 


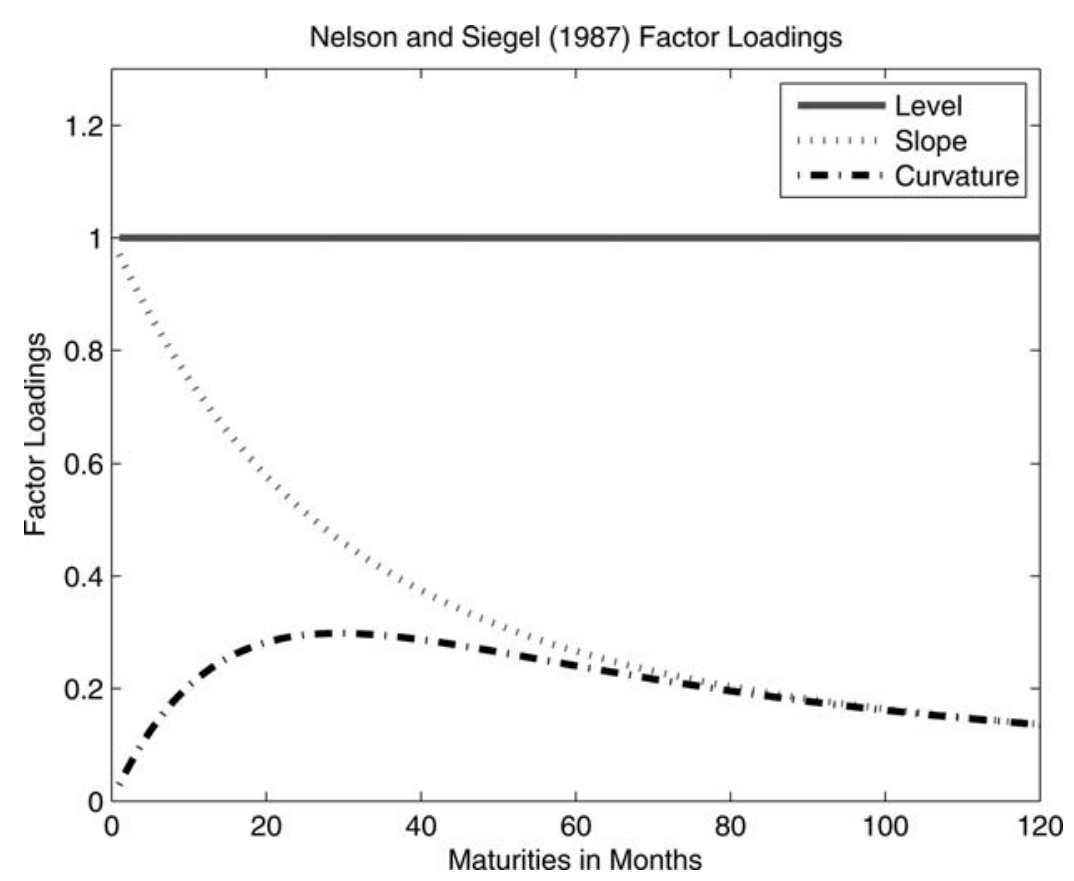

starting one month from the current date. As we approach the maturity date for the December 2009 contract, the one-year forward rate gradually becomes the one-year spot rate. So, as we observe the implied forward convenience yields through time, the successive observations lie at different points along the forward curve.

In order to create a standardized presentation of the implied forward curve, we employ a model of the term structure. The Nelson and Siegel (1987) model has been successfully applied to the term structure of interest rates, and so we experiment with applying it to the term structure of carbon convenience yields. Our implementation of the Nelson-Siegel model follows Diebold and $\mathrm{Li}$ (2006). On any given date, $t$, the convenience yield at maturity $\tau$ is written as a combination of three factors, $\beta_{1 t}, \beta_{2 t}$ and $\beta_{3 t}$ :

$$
y_{t}(\tau)=\beta_{1 t}+\beta_{2 t}\left(\frac{1-e^{-\lambda_{t} \tau}}{\lambda_{t} \tau}\right)+\beta_{3 t}\left(\frac{1-e^{-\lambda_{t} \tau}}{\lambda_{t} \tau}-e^{-\lambda_{t} \tau}\right)
$$

where the loading on each factor depends on the maturity, $\tau$, and a parameter $\lambda_{t}$. The loading on the first factor, $\beta_{1 t}$, is always 1 . The loading on the second factor, $\beta_{2 t}$, starts at 1 for maturity $\tau=$ 0 , and decays quickly and monitonically, approaching 0 as the maturity goes to infinity. The loading on the third factor, $\beta_{3 t}$, starts at 0 for maturity $\tau=0$, then first increases before peaking and then decaying quickly and monitonically, approaching 0 as the maturity goes to infinity. The rate of decay on the loadings for factors $\beta_{2 t}$ and $\beta_{3 t}$ are determined by the parameter $\lambda .^{21}$ The maturity structure of the loadings are plotted in Figure 6 . Corresponding to the maturity structure, the first 
Figure 7: Phase 2 Nelson-Siegel Factors

Beta 1

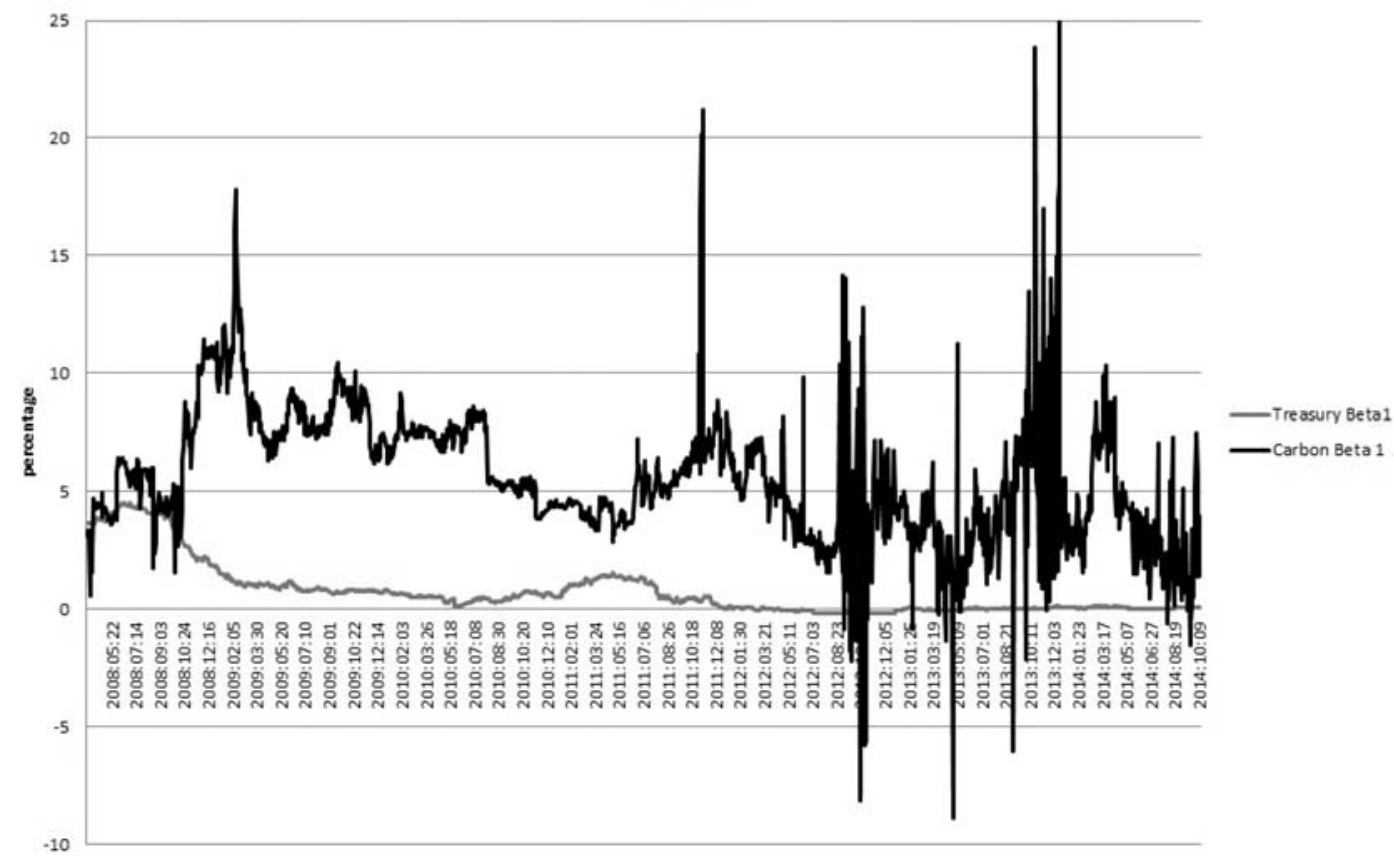

factor is known as the long-term factor, the second as the short-term factor and the third as the medium term factor. For interest rates, Diebold and Li (2006) illustrate that the time series of the fitted long-term factor matches the ten-year yield, the fitted short-term factor matches the spread between the ten-year and the three-month yield, and the medium term factor matches twice the two-year yield minus the sum of the three-month and the ten-year yield. Correspondingly, the first factor is also said to capture the level of the yield curve, the second factor the slope of the yield curve and the third factor the curvature.

In comparison to Trück et al. (2012) our factor weights are held constant, although not too dissimilar to the factor weights reported by Trück et al. (2012). In addition while Trück et al. (2012) apply their factor analysis to the price series, our analysis examines yields. ${ }^{22}$ However, although our model examines the case of yields, there is an important distinction between our methodology and previous models from the term structure of interest rates literature. In the standard application, see Diebold and Li (2006), the holding periods $(\tau)$ remain constant throughout. In our analysis the holding period $\tau$, as discussed earlier in this section, is not constant, but changes (falls) as we approach expiry for each contract. Although the quotation of the yield has been standardized, such that all carbon yields are on a continuously compounded basis, the window of time (holding period, $\tau$ ) cannot be standardized. However, the beta's that we report are standardized and so can be interpreted and compared with the beta's reported from the term structure of interest rate literature. We use both the spot and the futures data to fit the term structure curve. Figures 7, 8 and 9

22. Our analysis applies the Nelson and Siegel (1987) model to carbon yields when examining the spot-futures relationship. However, when examining consecutive futures contracts, forward rates are derived and the Nelson and Siegel (1987) model is adjusted to take account of the use of forward rates. See appendix for a complete derivation. 
Figure 8: Phase 2 Nelson-Siegel Factors

Beta 2

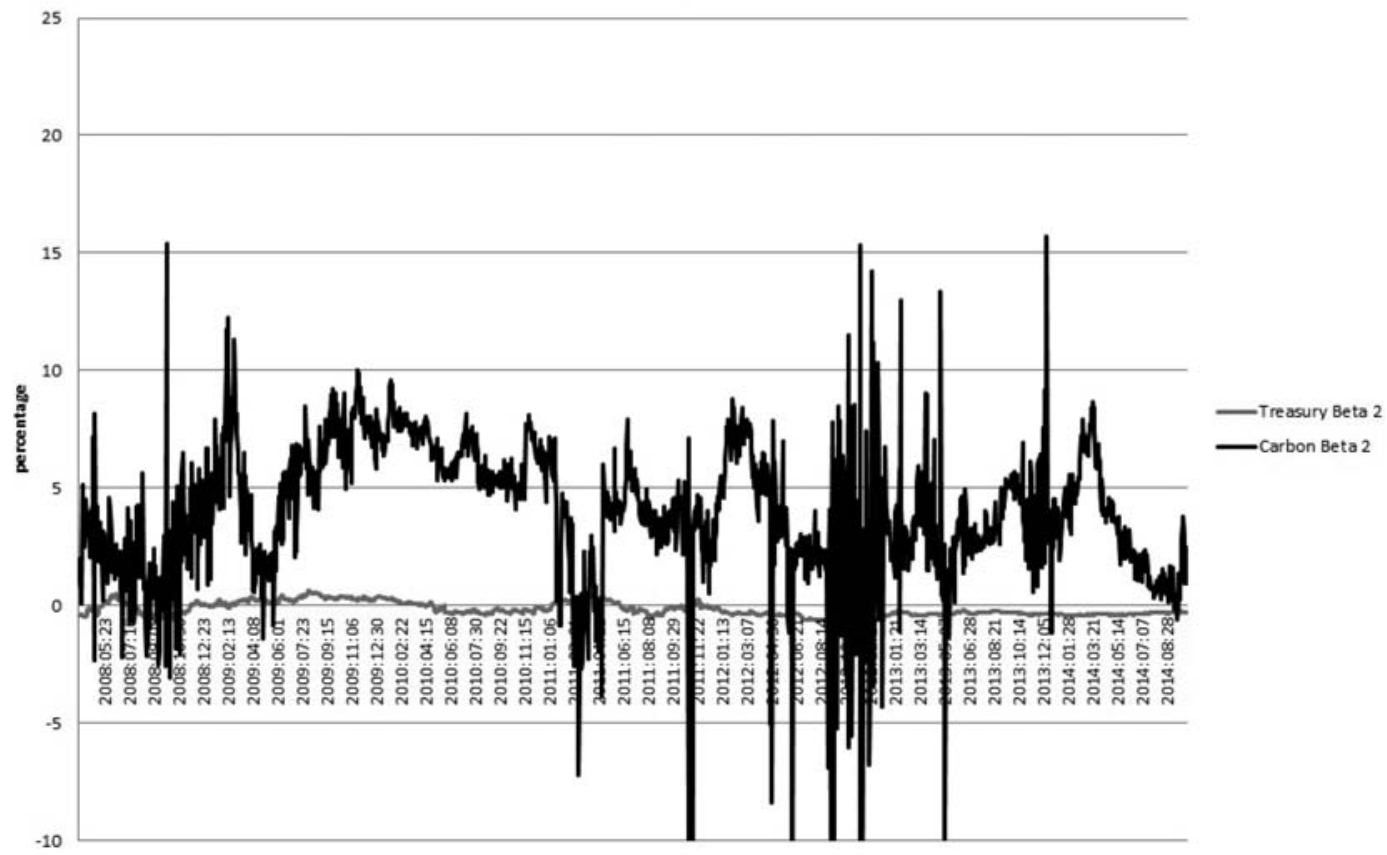

Figure 9: Phase 2 Nelson-Siegel Factors

Beta 3

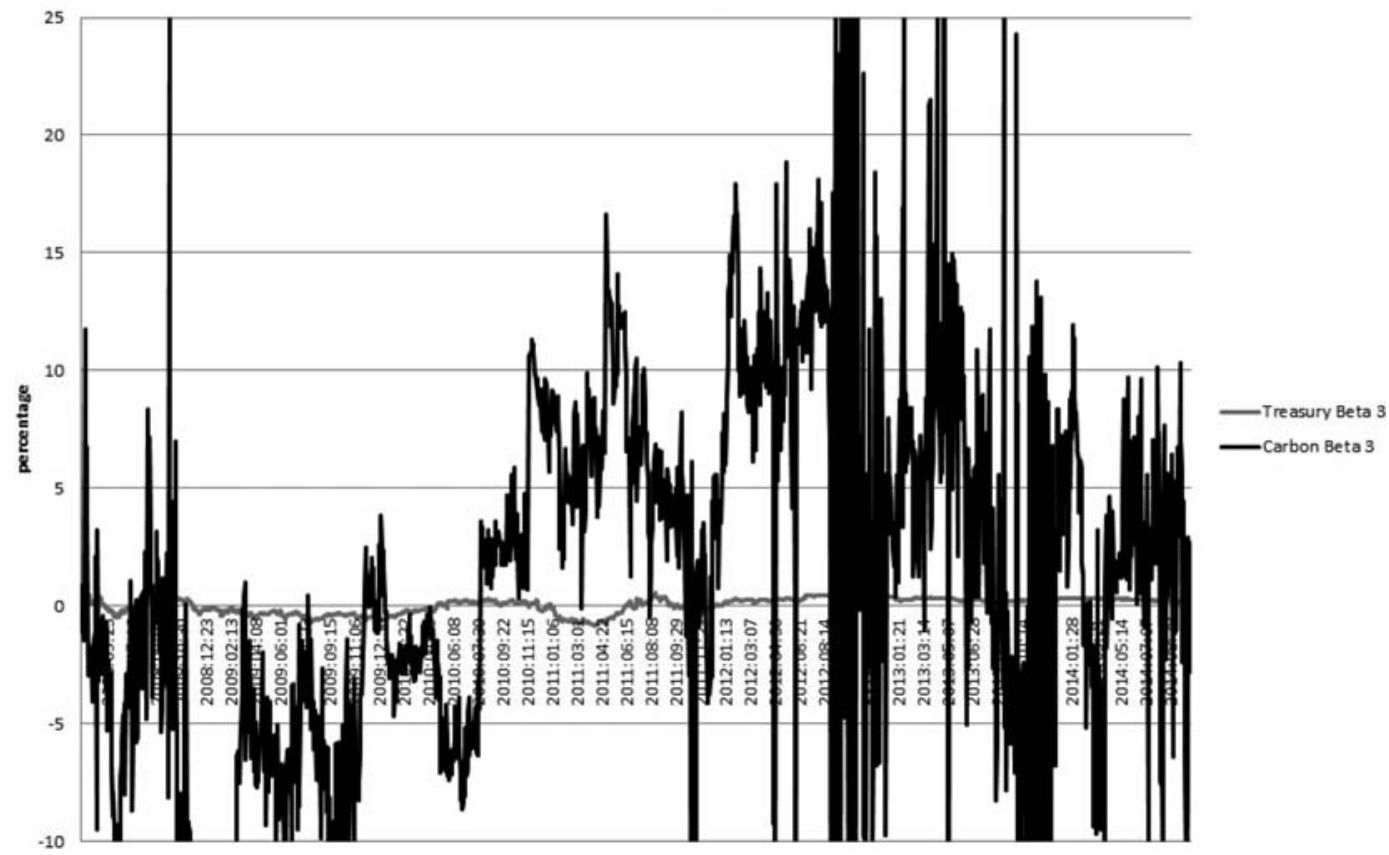

Copyright (C) 2016 by the IAEE. All rights reserved. 
report the time series of fitted factors, $\beta_{1 t}, \beta_{2 t}$ and $\beta_{3 t}$. Clearly the fitted parameters are dramatically more volatile than is the case for the term structure of interest rates. One striking feature is the gradual shift of the fitted values for $\beta_{3 t}$ from negative to positive.

The preceding material in sections 3.2, 3.3 and 4 establishes that the difference between the spot and futures prices of carbon or the difference between successive futures prices is regularly too large and too volatile to be explained by the cost of money as measured by government yields. The same result holds using other data measuring the cost of money to different parties. For example, we reproduced all of our results for Euribor rates, and while it moves the level of the discrepancy between spot and futures, the same basic results hold. The implied convenience yield is too large and varies too dramatically to be explained by market interest rates, regardless of which rate one employs. This can be seen by looking directly at the time series for the implied convenience yield and comparing it against the candidate rate. Of course, other factors not reflected in these market interest rates may allow the implied convenience yield to range widely around those rates, including sharp changes to financial constraints due to the financial crisis. That is exactly what our analysis of the data is intended to highlight.

\section{CONCLUSION}

The term structure of carbon spot and futures prices has behaved quite differently from what one might have expected from the received theory based on arbitrage across spot and futures. The EU-ETS allows allowances to be banked from one year to the next, at no penalty, with the important exception of the seam between Phase 1 and Phase 2 at year-end 2007. The cost of storing allowances is miniscule, and there is no obvious benefit to holding a supply of physical allowances as there is for physical commodities. Therefore, the main difference between a spot and future carbon allowance is the opportunity cost of money paid for the spot allowance. That is, the term structure of carbon prices should primarily reflect the term structure of interest rates. However, the data indicates otherwise.

Early in the history of the system, spot allowances were expensive relative to futures. That is, the futures price lay below the cost of carry price defined by the spot price grown at the rate of interest. Then, in 2008, the relationship reversed so that spot allowances became cheap relative to futures. That is, the futures price lies above the cost of carry price defined by the spot price grown at the rate of interest. Futures have remained expensive ever since. The size of the premium is quite large, with futures prices often embodying an implied convenience yield in the neighborhood of $-4 \%$ and $-6 \%$ and sometimes higher. This implied negative convenience yield moves around a significant amount.

This negative convenience yield is an important fact. It may reflect the lack of arbitrage due to financial constraints. The considerable fluctuations in the implied convenience yield may reflect how dramatically the marginal value of cash was fluctuating due to the financial crises in these years. Another factor should also be considered, and that is that these prices reflect something real about the market's view of the value of spot and futures positions. A negative convenience yield implies that the holder of a spot allowance expects to pay a price for holding the physical allowance. This would make sense if, for example, the holder of a physical allowance worried about changes to the rules of the system that (1) undermined the value of the physical allowance, but (2) not the value of a futures contract. Notice that expectations about the future level of the annual emissions cap would not qualify as such a worry since that would affect the value of both the spot and the future, it would shift the level of the term structure and not the slope of the term structure. The type of worry that would shift the slope would be, for example, a new regulation that taxed 
holders of physical allowances. Alternatively, a worry that regulators might change the bankability of allowances could shift the slope, for example disallowing the use of allowance vintages past a certain number of years. Although there have been lots of proposals floated in the EU to change the system in one way or another, none of these have been of the type that would obviously shift the slope of the yield curve. Nevertheless, the term structure of spot and futures prices we observe are consistent with this sort of fear.

In this paper, we have not tried to resolve which of these two explanations is right. Instead, we have focused on documenting the significant size and variability of the price discrepancy in order to highlight the need to better understand its determinants.

\section{ACKNOWLEDGMENTS}

This research was completed while Bredin was a Visiting Professor and Fulbright Scholar at the MIT Center for Energy and Environmental Policy Research (CEEPR). The authors would like to thank Bisser Alexandrov, Denny Ellerman, Emmanuel Fages, David Hone, Chris Knittel, John Reilly, Gerard O Reilly, Conall O Sullivan, Richard Schmalensee, Luca Taschini, Raphael Trotignon and Niven Winchester for valuable comments and seminar participants at MIT's Joint Program on the Science and Policy of Global Change, University College Dublin and conference participants at the International Association of Energy Economists European Conference in Rome in October 2014.

\section{REFERENCES}

Benz, E., Trück, S. (2009). Modeling the Price Dynamics of $\mathrm{CO}_{2}$ Emission Allowances. Energy Economics 31, 1, 4-15. http://dx.doi.org/10.1016/j.eneco.2008.07.003.

Bank of International Settlements (2005). Zero-Coupon Yield Curves, Technical Documentation, BIS Paper No. 25.

Borak, S, Härdle, W., Trück, S., Weron, R. (2006). Convenience Yields for $\mathrm{CO}_{2}$ Emission Allowance Futures Contracts, SFB 649 Discussion Paper 2006-076.

Bredin D., Muckley, C. (2011). An Emerging Equilibrium in the EU Emissions Trading Scheme, Energy Economics, 33, 353-362. http://dx.doi.org/10.1016/j.eneco.2010.06.009.

Bredin, D., Chen, J., Muckley, C. (2014a). Nascent Information Assimilation in the European Carbon Market, UCD Working Paper.

Bredin, D., Hyde, S., Muckley, C. (2014b). A Microstructure Analysis of the Carbon Finance Market, International Review of Financial Analysis, 34, 222-234. http://dx.doi.org/10.1016/j.irfa.2014.03.003.

Brennan, M.J. (1958). The Supply of Storage, American Economic Review, 48, 50-72.

Chevallier, J. (2009). Modelling the Convenience Yield in Carbon Prices Using Daily and Realized Measures, International Review of Applied Financial Issues and Economics, 1, 1, 56-73.

Chevallier, J. (2010). Modeling Risk Premia in $\mathrm{CO}_{2}$ Allowances Spot and Futures Prices. Economic Modelling 27, 3 , 717729. http://dx.doi.org/10.1016/j.econmod.2010.01.012.

Clo, S., Battles, S, Zoppoli, P. (2013), Policy Options to Improve the Effectiveness of the EU Emissions Trading Scheme: A Multi-criteria Analysis, Energy Policy, 57, 477-490. http://dx.doi.org/10.1016/j.enpol.2013.02.015.

Diebold, F.X., Li, C. (2006). Forecasting the Term Structure of Government Bond Yields. Journal of Econometrics 130, 337-364. http://dx.doi.org/10.1016/j.jeconom.2005.03.005.

EC. (2013). The EU Emissions Trading System (EU ETS): Factsheet, October.

European Central Bank (2008). The New Euro Area Yield Curves, Monthly Bulletin, February, 95-103.

Ellerman, D., Buchner, B. (2007). The European Union Emissions Trading Scheme: Origins, Allocation, and Early Results, Review of Environmental Economics and Policy, 1, 1, 66-87. http://dx.doi.org/10.1093/reep/rem003.

Ellerman, D., Joskow, P. (2008). The European Union's Emissions Trading System in Perspective, Pew Center on Global Climate Change, Washington, D.C., (May). Available at: http://www.pewclimate.org/docUploads/EU-ETS-InPerspectiveReport.pdf. 
Ellerman, D., Convery, F., de Perthuis, C. (2010). Pricing Carbon The European Union Emissions Trading Scheme, Cambridge University Press, Cambridge, UK.

Ellerman, D., Marcantonini, C., Zaklan, A. (2014). The EU ETS: Eight Years and Counting, Robert Schuman Centre for Advanced Studies, Climate Policy Research Unit, RCAS 2014/14.

Gregory, A., Hansen, B.E. (1996a). Residual-Based Tests for Cointegration in Models with Regime Shifts, Journal of Econometrics, 70, 99-126. http://dx.doi.org/10.1016/0304-4076(69)41685-7.

Gregory, A., Hansen, B.E. (1996b). Tests for Cointegration in Models with Regime and Trend Shifts, Oxford Bulletin of Economics and Statistics, 58, 555-560. http://dx.doi.org/10.1111/j.1468-0084.1996.mp58003008.x.

Grosjean, G., Acworth, W., Flachsland, C. and Marschinski, R. (2014). After Monetary Policy, Climate Policy: Is Delegation the Key to EU ETS Reform?, Climate Policy, MCC Working Paper February.

Johansen, S. (1988). Statistical Analysis of Cointegrating Vectors, Journal of Economic Dynamics and Control 12, 231254. http://dx.doi.org/10.1016/0165-1889(88)90041-3.

Johansen S. (2002). A Small Sample Correction for the Test of Cointegrating Rank in the Vector Autoregressive Model, Econometrica 70, 1929-1961. http://dx.doi.org/10.1111/1468-0262.00358.

Joyeux, R., Milunovich, G. (2010). Testing Market Efficiency in the EU Carbon Futures Market, Applied Financial Economics, 20, 1-7. http://dx.doi.org/10.1080/09603101003636220.

Kalaitzogloua, I., Ibrahimb, B.M. (2013). Does Order Flow in the European Carbon Futures Market Reveal Information?, Journal of Financial Markets, 16, 3, 604-635. http://dx.doi.org/10.1016/j.finmar.2012.11.002.

Koch, N., Fuss, S., Grosjean, G., Edenhofer, O. (2014). Causes of the EU ETS Price Drop: Recession, CDM, Renewable Policies or a Bit of Everything? New Evidence, Energy Policy, 73, 676-685. http://dx.doi.org/10.1016/ j.enpol.2014.06.024.

Lumsdaine, R. L., Papell, D. H. (1997). Multiple Trend Breaks and the Unit Root Hypothesis, Review of Economics and Statistics, 79, 2, 212-218. http://dx.doi.org/10.1162/003465397556791.

Madalena, M., Pinho, C. (2011). Risk Premia in $\mathrm{CO}_{2}$ Allowances: Spot and Futures Prices in the EEX Market. Management of Environmental Quality: An International Journal 22, 5, 550-565. http://dx.doi.org/10.1108/14777831111159699.

Neuhoff, K., Schopp, A., Boyd, R., Stelmakh, K., Vasa, A. (2012). Banking of Surplus Emissions Allowances: Does the Volume Matter?, Discussion Papers of DIW Berlin 1196, DIW Berlin, German Institute for Economic Research.

Nelson, C.R., Siegel, A.F. (1987). Parsimonious Modelling of the Yield Curve, Journal of Business, 60, 473-489. http:// dx.doi.org/10.1086/296409.

Nield, K., Pereira, R. (2011). Fraud on the European Union Emissions Trading Scheme: Effects, Vulnerabilites and Regularitory Reform, European Energy and Environmental Law Review, 20, 6, 255-289.

Parsons, J. E., Ellerman, A.D., Feilhauer, S. (2009). Designing a U.S. Market for $\mathrm{CO}_{2}$, Journal of Applied Corporate Finance, 21, 79-86. http://dx.doi.org/10.1111/j.1745-6622.2009.00218.x.

Phillips, P., Perron, P. (1988). Testing for a Unit Root in Time Series Regression, Biometrica, 75, 335-346. http://dx.doi.org/ 10.1093/biomet/75.2.335.

Pindyck, R. S. (2001). The Dynamics of Commodity Spot and Futures Markets: A Primer, The Energy Journal, 22, 3, 129. http://dx.doi.org/10.5547/ISSN0195-6574-EJ-Vol22-No3-1.

Shambaugh, J. C. (2012). The Euro's Three Crises, Brookings Papers on Economic Activity, Spring, 157-231. http:// dx.doi.org/10.1353/eca.2012.0006.

Trück, S., Härdle, W., Weron, R. (2012). The Relationship Between Spot and Futures $\mathrm{CO}_{2}$ Emission Allowance Prices in the EU ETS, mimeo.

Uhrig-Homburg, M. and Wagner, M. (2009) Futures Price Dynamics of $\mathrm{CO}_{2}$ Emission Allowances: An Empirical Analysis of the Trial Period, Journal of Derivatives, 17, 2, 73-88. http://dx.doi.org/10.3905/JOD.2009.17.2.073.

\section{APPENDIX: INTEREST RATES VS. CARBON RATES}

\subsection{Interest Rates}

Following the notation in Diebold and Li (2006), at calendar date $t$, the price of a $\tau$-period discount bond, i.e., paying $\$ 1$ at calendar date $t+\tau$ is $P_{t}(\tau)$. We are used to thinking in terms of yields: the yield to maturity on this bond, $y_{t}(\tau)$, expressed as a continuously compounded rate, is defined by:

Copyright (C) 2016 by the IAEE. All rights reserved. 


$$
P_{t}(\tau) \equiv e^{y_{t}(\tau) \tau}
$$

so that

$$
y_{t}(\tau)=\frac{1}{\tau} \ln \left(P_{t}(\tau)\right)
$$

A less natural, but more useful way to describe the term structure of interest rates is in terms of the instantaneous forward rate, $f_{t}(\tau)$, which is defined by:

$$
F_{t}(\tau) \equiv-\frac{P_{t}^{\prime}(\tau)}{P_{t}(\tau)}
$$

The yield to maturity can be calculated from the instantaneous forward rates as:

$$
y_{t}(\tau)=\frac{1}{\tau} \int_{0}^{\tau} f_{t}(u) d u
$$

This is an average of the instantaneous rates from calendar date $t$ to calendar date $t+\tau$. An alternative type of forward rate is defined over a window of time, e.g., from calendar date $T_{1}=t+\tau_{1}$ to date $T_{2}=t+\tau_{2}$, where $k=T_{2}-T_{1}=\tau_{2}-\tau_{1}$ is the length of the window of time. Expressed as a continuously compounded rate, this $k$-period forward rate is given by:

$$
g_{t}\left(\tau_{1}, \tau_{2}\right)=\frac{1}{\tau_{2}-\tau_{1}} \int_{\tau_{1}}^{\tau_{2}} f_{t}(u) d u
$$

This is an average of the instantaneous rates across that window of time. Recognizing these multiple ways of representing the same term structure, we can write:

$$
P_{t}(\tau)=e^{-\int_{0}^{\tau} f_{t}(u) d u}=e^{-g_{t}(0, \tau) \tau}=e^{-y_{t}(\tau) \tau}
$$

\subsection{Carbon Rates}

A similar array of rates can be constructed from the term structure of carbon futures prices. Let $F_{t}(\tau)$ be the futures price of a contract at calendar date $t$ with delivery $\tau$-periods ahead. For the special case of $\tau$, we call this the spot price, $S_{t} \equiv F_{t}(0)$. Define the carbon yield, $z_{t}(\tau)$, expressed as a continuously compounded rate, by:

$$
F_{t}(\tau) \equiv S_{t} e^{z_{t}(\tau) \tau}
$$

so that:

$$
z_{t}(\tau)=\frac{1}{\tau} \ln \left(\frac{F_{t}(\tau)}{s_{t}}\right)
$$


The instantaneous forward rate for carbon, $\gamma_{t}(\tau)$, as:

$$
\gamma_{t}(\tau) \equiv-\frac{F_{t}^{\prime}(\tau)}{F_{t}(\tau)}
$$

The yield to maturity can be calculated from the instantaneous forward rates as:

$$
z_{t}(\tau)=\frac{1}{\tau} \int_{0}^{\tau} \gamma_{t}(u) d u
$$

An alternative type of forward rate for carbon is defined over a window of time, e.g., from calendar date $T_{1}=t+\tau_{1}$ to date $T_{2}=t+\tau_{2}$, where $k=T_{2}-T_{1}=\tau_{2}-\tau_{1}$ is the length of the window of time. Expressed as a continuously compounded rate, this $k$-period forward rate is given by:

$$
\eta_{t}\left(\tau_{1}, \tau_{2}\right)=\frac{1}{\tau_{2}-\tau_{1}} \int_{\tau_{1}}^{\tau_{2}} \gamma_{t}(u) d u
$$

This is an average of the instantaneous rates across that window of time. Recognizing these multiple ways of representing the same term structure, we can write:

$$
F_{t}(\tau)=S_{t} e^{-\int_{0}^{\tau} \gamma_{t}(u) d u}=S_{t} e^{-\eta_{t}(0, \tau) \tau}=S_{t} e^{-z_{t}(\tau) \tau}
$$

Expanding upon this representation, we can also express the alternative forward rate for carbon directly in terms of the prices of two futures contracts:

$$
\eta_{t}\left(\tau_{1}, \tau_{2}\right)=\frac{1}{\tau_{2}-\tau_{1}} \ln \left(\frac{F_{t}\left(\tau_{2}\right)}{F_{t}\left(\tau_{1}\right)}\right)
$$

We can compare the yields and forward rates on carbon against the yields and forward rates in the money market:

$$
\begin{array}{ccc}
\text { Spot Carbon Discount } & = & z_{t}(\tau)-y_{t}(\tau) \\
\text { Nearby Futures Carbon Discount } & = & \eta_{t}\left(\tau_{1}, \tau_{2}\right)-g_{t}\left(\tau_{1}, \tau_{2}\right)
\end{array}
$$

\subsection{Nelson and Siegel (1987) Parameter Estimation}

Drawing on Diebold and Li (2006), we have the Nelson and Siegel (1987) instantaneous forward rate curve:

$$
f_{t}(\tau)=\beta_{1 t}+\beta_{2 t} e^{-\lambda_{t} \tau}+\beta_{3 t} \lambda_{t} e^{-\lambda_{t} \tau}
$$

and the corresponding yield curve:

$$
y_{t}(\tau)=\beta_{1 t}+\beta_{2 t}\left(\frac{1-e^{-\lambda_{t} \tau}}{\lambda_{t} \tau}\right)+\beta_{3 t}\left(\frac{1-e^{-\lambda_{t} \tau}}{\lambda_{t} \tau}-e^{-\lambda_{t} \tau}\right)
$$


Using the definition of the average forward rate over a window of time as the integral of the instantaneous forward rate over that window, and the definition of the yield as the integral of the instantaneous forward rate over a window starting at $t$, we can derive the Nelson and Siegel (1987) expression for the average forward rate over a window of time:

$$
\begin{aligned}
g_{t}\left(\tau_{1}, \tau_{2}\right)= & \frac{1}{\tau_{2}-\tau_{1}} \int_{\tau_{1}}^{\tau_{2}} f_{t}(u) d u \\
= & \frac{1}{\tau_{2}-\tau_{1}}\left(\int_{0}^{\tau_{2}} f_{t}(u) d u-\int_{0}^{\tau_{1}} f_{t}(u) d u\right) \\
= & \frac{1}{\tau_{2}-\tau_{1}}\left(\tau_{2} \frac{1}{\tau_{2}} \int_{0}^{\tau_{2}} f_{t}(u) d u-\tau_{1} \frac{1}{\tau_{1}} \int_{0}^{\tau_{1}} f_{t}(u) d u\right) \\
= & \left.\frac{1}{\tau_{2}-\tau_{1}}\left(\tau_{2} y_{t}\left(\tau_{2}\right)-\tau_{1} y_{t} \tau_{1}\right)\right) \\
= & \frac{\tau_{2}}{\tau_{2}-\tau_{1}} y_{t}\left(\tau_{2}\right)-\frac{\tau_{1}}{\tau_{2}-\tau_{1}} y_{t}\left(\tau_{1}\right) \\
= & \left.\frac{\tau_{2}}{\tau_{2}-\tau_{1}}\left[\beta_{1 t}+\beta_{2 t}\left(\frac{1-e^{-\lambda_{t} \tau_{2}}}{\lambda_{t} \tau_{2}}\right)+\beta_{3 t} \frac{1-e^{-\lambda_{t} \tau_{2}}}{\lambda_{t} \tau_{2}}-e^{-\lambda_{t}} \tau_{2}\right)\right] \\
& \left.-\frac{\tau_{1}}{\tau_{2}-\tau_{1}}\left[\beta_{1 t}+\beta_{2 t}\left(\frac{1-e^{-\lambda_{t} \tau_{1}}}{\lambda_{t} \tau_{1}}\right)+\beta_{3 t} \frac{1-e^{-\lambda_{t} \tau_{1}}}{\lambda_{t} \tau_{1}}-e^{-\lambda_{t}} \tau_{1}\right)\right] \\
= & \beta_{1 t}+\beta_{2 t}\left(\frac{\tau_{2}}{\tau_{2}-\tau_{1}}\left(\frac{1-e^{-\lambda_{t} \tau_{2}}}{\lambda_{t} \tau_{2}}\right)-\frac{\tau_{1}}{\tau_{2}-\tau_{1}}\left(\frac{1-e^{-\lambda_{t} \tau_{1}}}{\lambda_{t} \tau_{1}}\right)\right) \\
& +\beta_{3 t}\left(\frac{\tau_{2}}{\tau_{2}-\tau_{1}}\left(\frac{1-e^{-\lambda_{t} \tau_{2}}}{\lambda_{t} \tau_{2}}-e^{-\lambda_{t}} \tau_{2}\right)-\frac{\tau_{1}}{\tau_{2}-\tau_{1}}\left(\frac{1-e^{-\lambda_{t} \tau_{1}}}{\lambda_{t} \tau_{1}}-e^{-\lambda_{t} \tau_{1}}\right)\right)
\end{aligned}
$$

The same relationship can be applied to the average forward carbon rates:

$$
\begin{aligned}
\eta_{t}\left(\tau_{1}, \tau_{2}\right)= & \beta_{1 t}^{c}+\beta_{2 t}^{c}\left(\frac{\tau_{2}}{\tau_{2}-\tau_{1}}\left(\frac{1-e^{-\lambda_{t}^{c} \tau_{2}}}{\lambda_{t}^{c} \tau_{2}}\right)-\frac{\tau_{1}}{\tau_{2}-\tau_{1}}\left(\frac{1-e^{-\lambda_{t}^{c} \tau_{1}}}{\lambda_{t}^{c} \tau_{1}}\right)\right) \\
& +\beta_{3 t}\left(\frac{\tau_{2}}{\tau_{2}-\tau_{1}}\left(\frac{1-e^{-\lambda_{t}^{c} \tau_{2}}}{\lambda_{t}^{c} \tau_{2}}-e^{-\lambda_{t}^{c} \tau_{2}}\right) \frac{\tau_{1}}{\tau_{2}-\tau_{1}}\left(\frac{1-e^{-\lambda_{t}^{c} \tau_{1}}}{\lambda_{t}^{c} \tau_{1}}-e^{-\lambda_{t}^{c} \tau_{1}}\right)\right)
\end{aligned}
$$

Then, taking $\lambda_{t}^{c}$ as given, the parameters $\beta_{1 t}^{c}, \beta_{2 t}^{c}$ and $\beta_{3 t}^{c}$ can be estimated from carbon futures prices using OLS. 


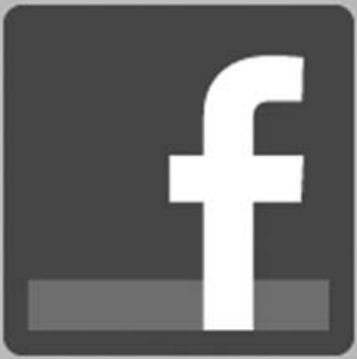

Connect with

\section{IAEE}

on facebook

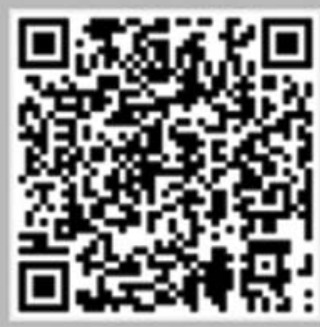

